Journal of Educational

and Psychological Sciences

Volume (6), Issue (10): 28 Feb 2022

P: 133 - 160

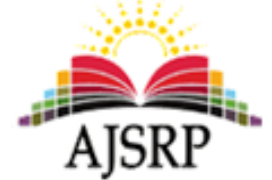

ISSN: 2522- 3399
مجلة العلوم

التربوية والنفسية

المجلد (6))، العدد (10): 28 فبراير 2022 م

ص: 133 - 160

\title{
Psychometric properties of Snijders- Omen test to measure non- verbal intelligence according to item response theory- on a sample of secondary school students in the city of Makkah
}

\author{
Abdulrahman Jmman Alzahrani \\ College of Education || Umm Al- Qura University || KSA
}

\begin{abstract}
The current study aimed at creating Psychometric characteristics to test Sinjders- Oomen to measure non- verbal
\end{abstract} intelligence, and find criteria for explanation of ability to individuals, and the classified approach was used in SinjersOomen. A secondary school in Makkah city, the results showed that the most appropriate data model is Two- Parameter Model, after ensuring the assumptions of Item Response Theory for the examination of the study data, and are Unidimensional using the Nonparametric factor analysis method $T=2.13$ "For a stout method at the level of significance ( $P$ $=0.016)$, a statistically function, It explains that only one latent variable is sufficient to explain the variance of individuals' performance on the test. The paragraph analysis method was used using noharm3 software and the value of the square root index for the average boxes $(\mathrm{RMSR}=0.007)$ was very close to scratch. The value of the Tanaka Index for Good Match (0.977) is very close one in the correct one, and the values point to Goodness of fit to the Unidimensional model. The method of detection of local independence was used for paragraphs Yen Q3, and the appropriateness of individuals and paragraphs for the Two- parameter Logistic. The results confirmed that the test paragraphs included a wide range of difficulty and tend to graduate at the difficult level and that the average normative mistakes of the difficulty of the difficulty of the difficulty (0.151) is a standard deviation (1.949), small values indicated that values were highly appreciated, as well as a function Test information in the light of the item response theory for the separation of the organs, the capacity of individuals $(\theta)$ has also been found for the corresponding to each degree of crude college on the test, and the standards explained in the performance of the performance on the test. Based on the results presented several recommendations and proposals:

1- Provide the opportunity for graduate students in measurement and evaluation for the exact details of item response theory.

2- Pay attention to the training of graduate students during systematic study on the use of existing response theoretical applications and applying what has been studied at the theoretical side.

3- Use the models of response to the disruption of the tests and psychological standards.

4- Restructuring psychological tests in the light of the models of response for the disruption.

The researcher also recommends the use of Sinjders- Oomen test or sealing the students with higher mental abilities in the Ministry of Education to detect talented intelligence in talented care centers. As well as in care centers for intelligence of deaf and mute and mutual disabilities and autism.

Keywords: Sinjders- Oomen test, non- verbal intelligence, psychometric properties, Item response theory, Two- parameter Logistic model. 


\title{
الخصائص السيكومترية لاختبار سنجدرس أومن Snijders- Oomen لقياس الذكاء غير اللفظي في ضوء نظرية الاستجابة للمفردة الاختبارية على عينة من طلاب الثانوية في مدينة مكة المكرمة
}

\author{
عبد الرحمن جمعان الزهراني \\ كلية التربية || جامعة أم القرى || المملكة العربية السعبودية الزهراني
}

المستخلص: هدفت الدراسة الحالية إلى إيجاد الخصائص السيكومترية لاختبار سنجدرس أومن لقياس الذكاء غير اللفظي، وايجاد الذاديات معايير

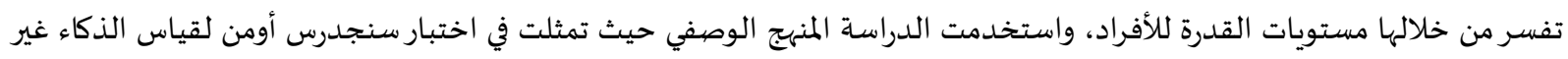

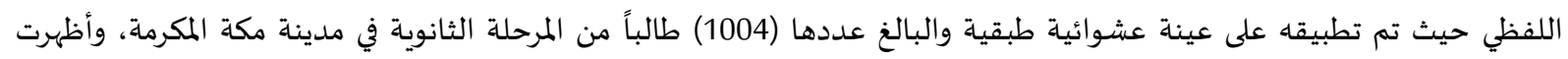

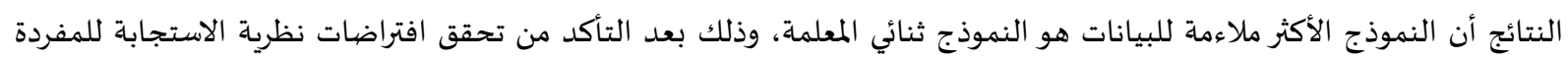

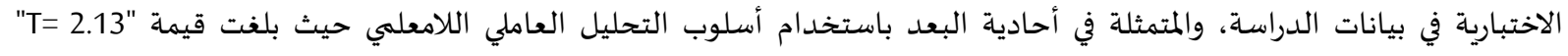

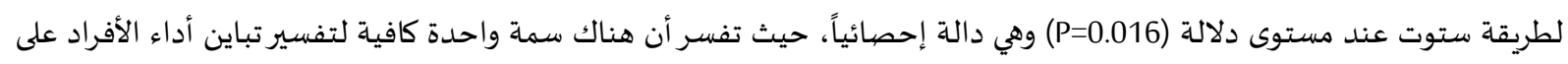

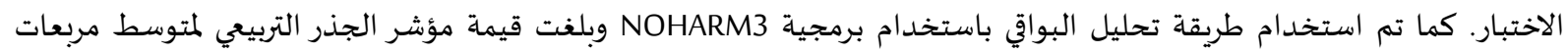

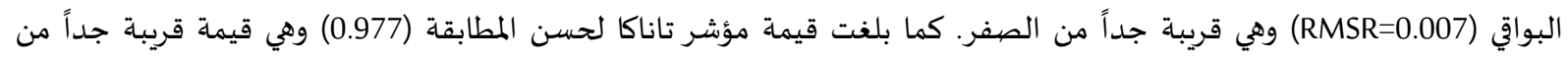

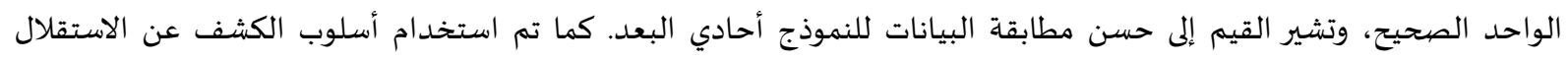

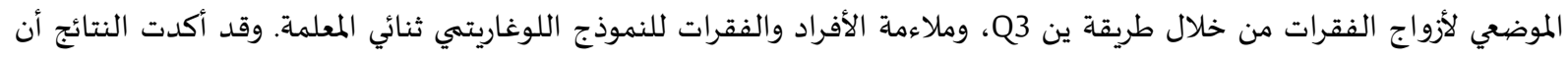

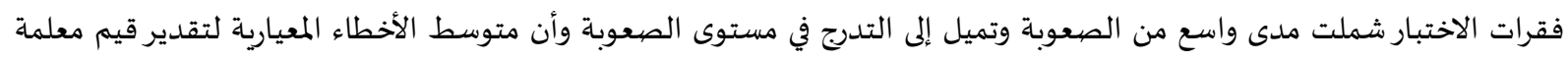

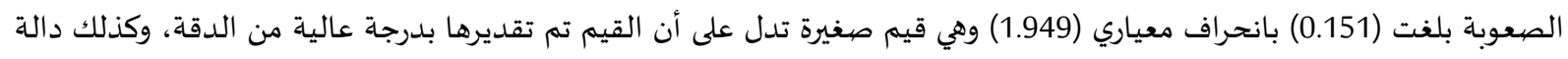

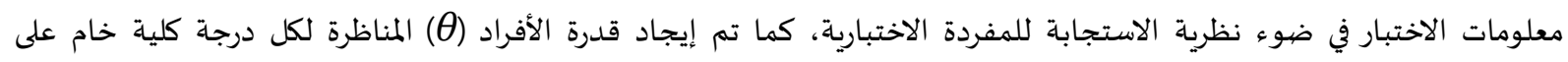

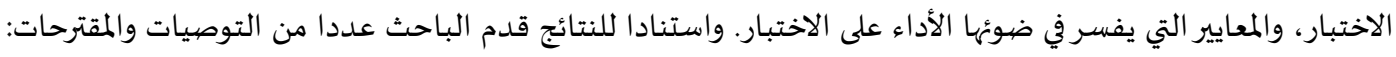

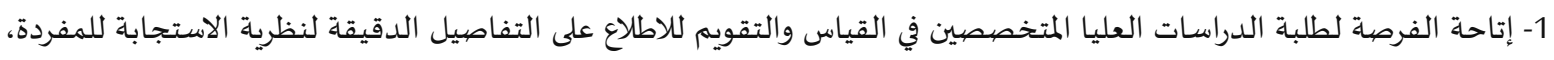

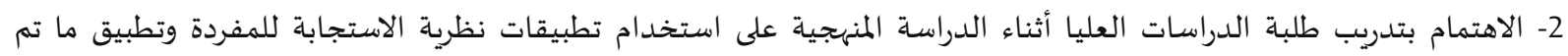

دراسته في الجانب النظري. 3- استخدام نماذج نظرية الاستجابة للمفردة الاختبارية في بناء الاختبارات والمقاييس النفائ النفسية.

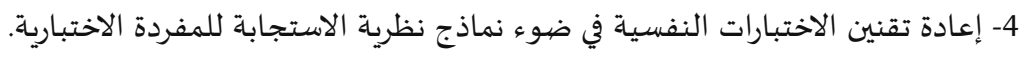

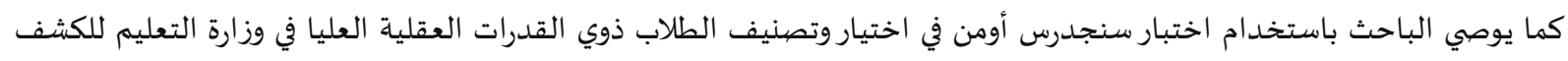

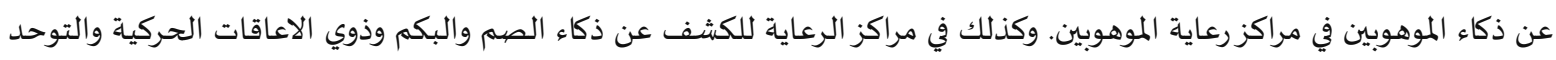
الكلمات المفتاحية: اختبار سنجدرس- أومن، ذكاء غير لفظي، الخصائص السيكومترية، نظرية الاستجابة للمفردة الاختبارية، النموذج اللوغاريتهي ثنائي المعلمة.

مقدمة.

بداية اختبارات الذكاء في أوائل عام 1900 حيث أبدت فرنسا برنامجاً تعليمياً إلزامياً، واعترافاً منها بأن

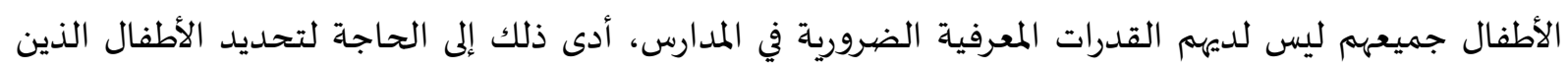

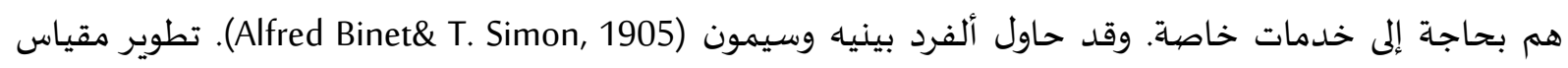
للذكاء واستغرق ذلك عدة أعوام. ونتيجة لجههودهما، ظهر مقياس بينيه- سيمون عام

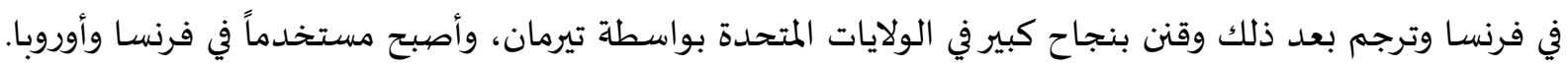

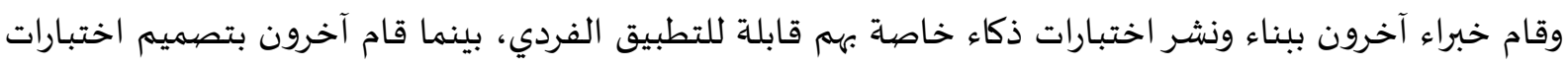


أخرى قابلة للتطبيق الجماعي حيث ركزت هذه الاختبارات على القدرات اللفظية والكمية وكذلك القدرات البصرية-

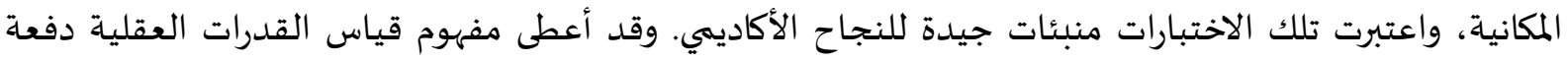

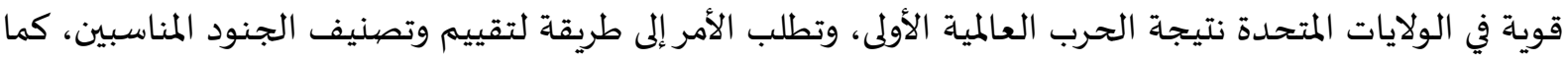

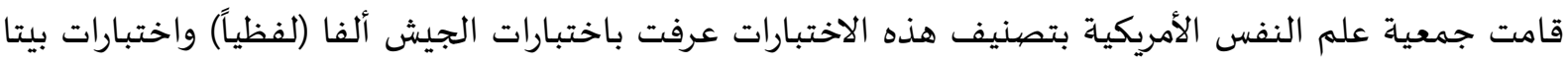

(غير لفظي). عقب ذلك طور وكسلر اختبار ذكاء اشتمل على مقاييس للقدرة اللفظية وغير اللفظية (علام، 2013).

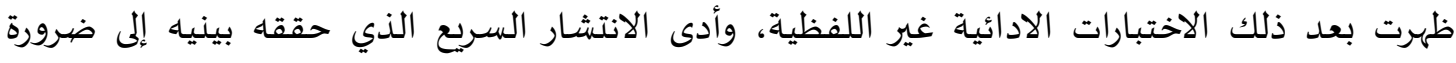

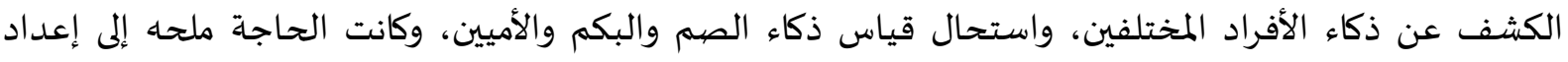

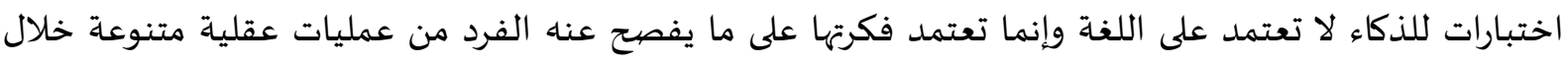

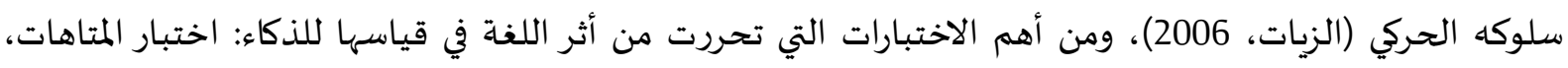

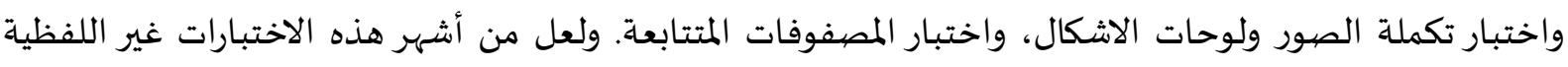
اختبار SON R6-40 الذي صممه سنجدرس وأومن Sinjders- Oomen نظرية الذكاء التي وضعها كاتل مatell عام 1971، والتي تقسّم الذكاء إلى سائل ومتبلور. ويقصيد بالذكاء السائل

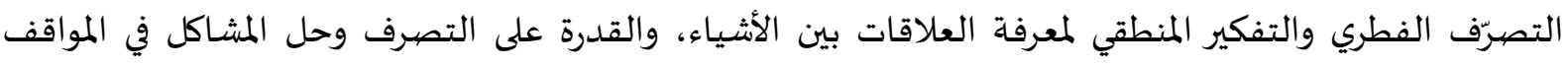

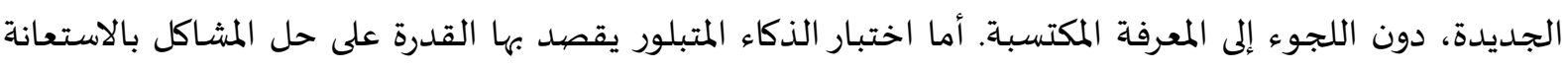

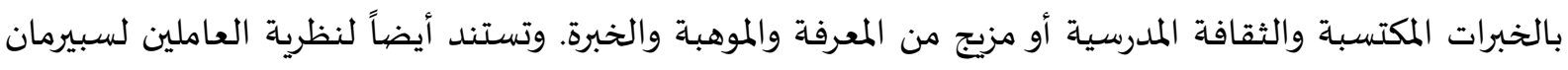
Two Factors Theory

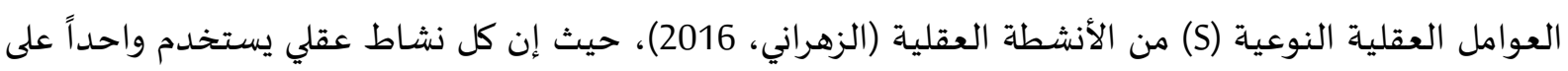
الاقل من العوامل الخاصة، بينما يشترك العامل العام في جميع صهور النشاط العندة العقلي.

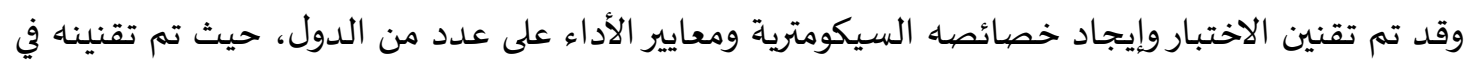

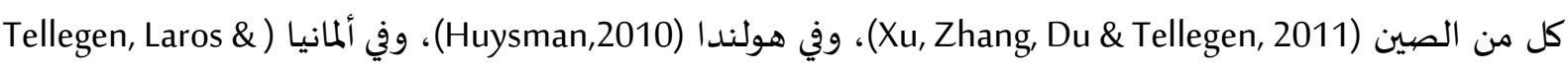

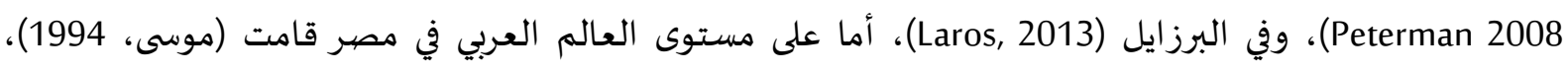

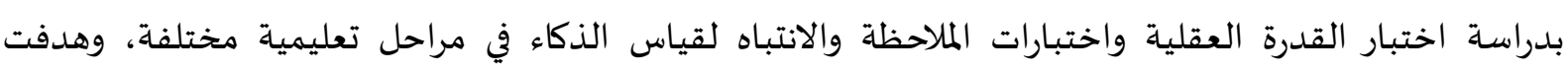

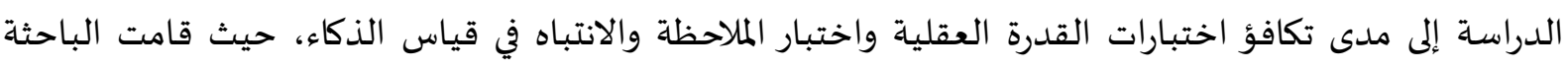
بتطبيق اختبار SON- R كأداة على عينة من البنين والبنات، حيث بلغ مجموع العينة (75) بمتوسط (16.85)

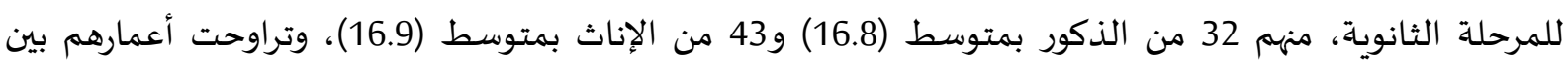

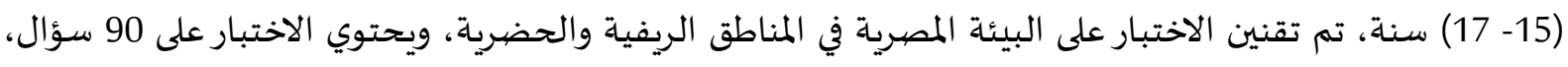

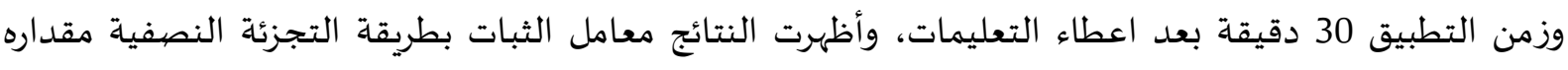

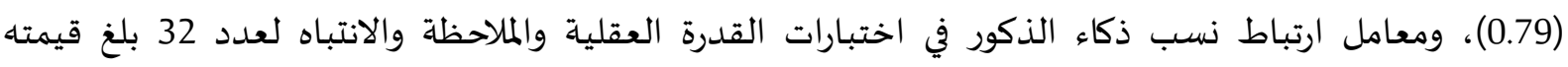

(0.20)، ولإناث لعدد 43 بلغ قيمته (0.33).

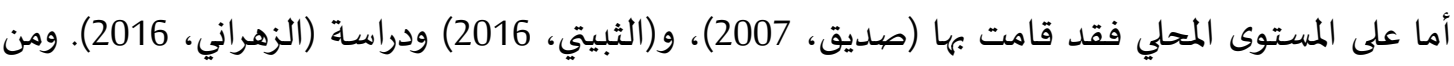

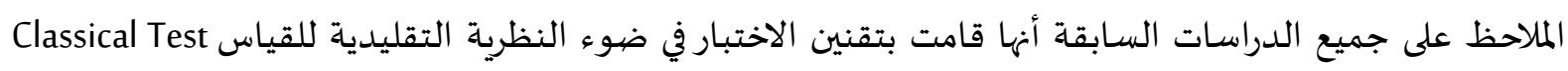
Theory

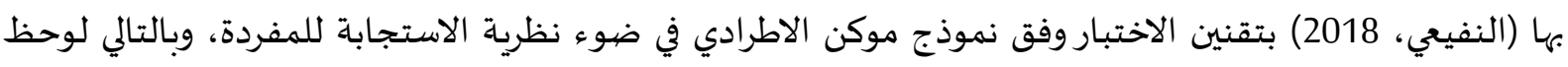

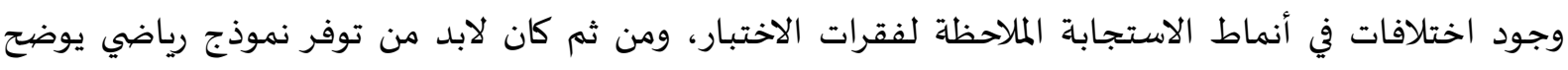
كيفية استجابة المفحوصين من مستويات مختلفة للقدرة على الفقرات، وكذلك مقارنة أداء المفحوصيين الذين 
يتقدمون لاختبارات مختلفة على الفقرات، بالإضافة إلى إمكانية تحليل الفقرة على مجموعات بمستويات قدرة تختلف عن المجموعة التي حللت الفقرات من خلال بياناتها(كروكر، الجينا، 2009).

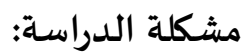

برز محور جديد في القياس النفسي والتربوي، وخصوصهاً في مجال تطوير الاختبارات، واتجه نحو القياس الموضوعي للمظاهر السلوكية. وأسفر عنه حلول لبعض مشككلات القياس التي أحدثتها نظرية القياس التقليدية (بيكر، 2010)، ألا وهو نظرية القياس الحديثة أو ما يسمى بنظرية الاستجابة للمفردة.

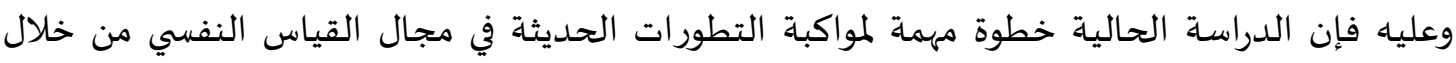
إيجاد الخصائص السيكومترية لاختبار سنجدرس أومن ومعايير تفسير الأداء في ضوء نظرية الاستجابة للمفردة

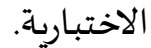

وبشكل أكثر دقة تتحدد مشكلة الدراسة في السؤال الرئيس التالي:

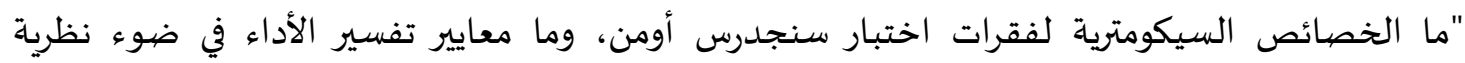

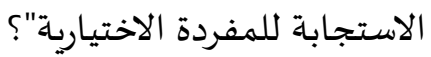

ويتفرع عن السؤال السابق الأسئلة التالية:

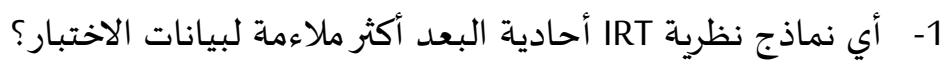

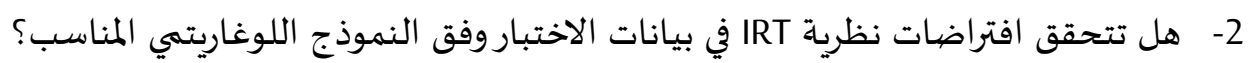

ويتفرع منه السؤالان الفرعيان الآتيان:

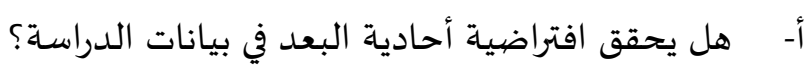

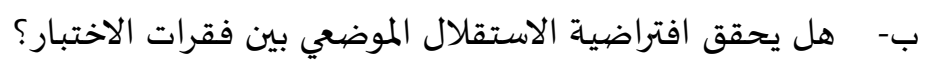

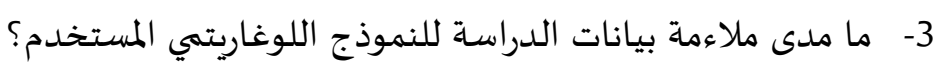

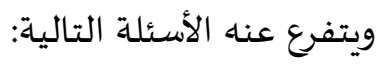

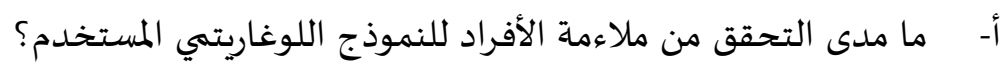

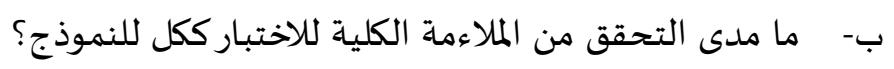

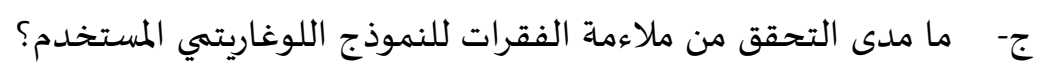

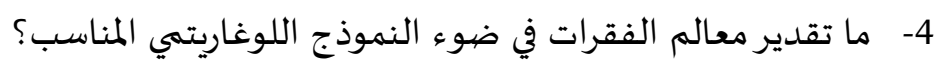

ويتفرع عنه الأسئلة التالية:

أ- ما خصائص وتقديرات بارامترات الاختبار؟

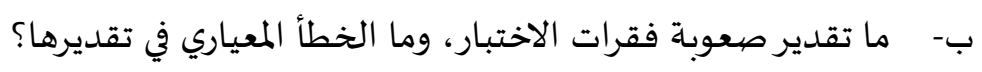

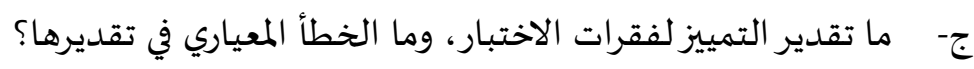

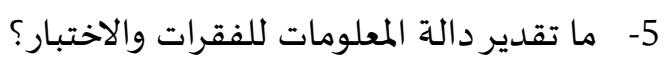

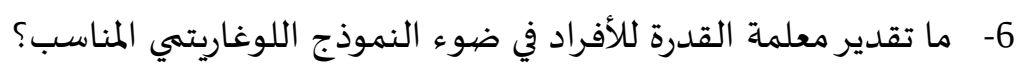

أهداف الدراسة:

هدفت الدراسة الحالية لإيجاد الخصائص السيكومترية لاختبار سنجدرس أومن لقياس الذكاء غير اللفظي

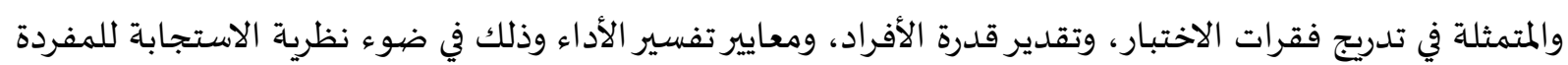


الاختبارية. وذلك لاستمراريه التطور الذي حدث في مجال القياس، وفي نشوء نظرية ذات أساس فلسفي قوي تجعلها

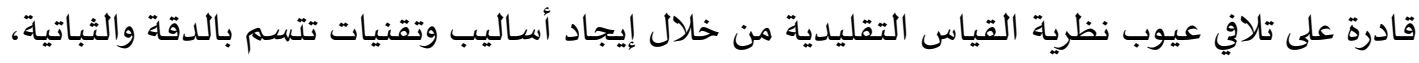

أهمية الدراسـة:

تكمن أهمية الدراسة في سعيها لتزويد المختصين في القياس النفسي والتربوي باختبار مقنن لقياس القدرة

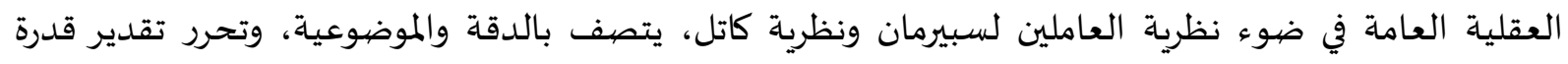
الأفراد من أثر معالم الفقرات، وتحرر تقدير معالم الفقرات من أثر قدرة الأفراد. وتؤكد هذه الدراسة ضرأه ضرورة إعادة

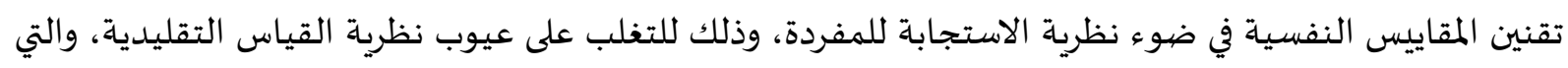
قننت في ضوئها غالبية المقاييس النفسية.

حدود الدراسـة: (n

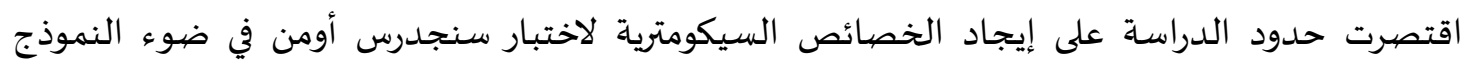

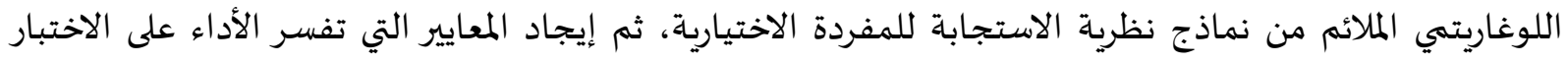

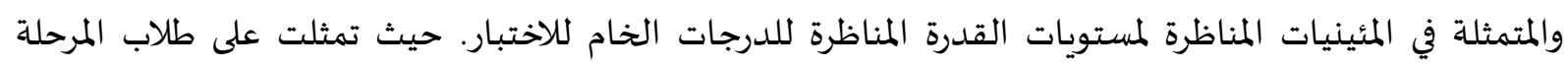

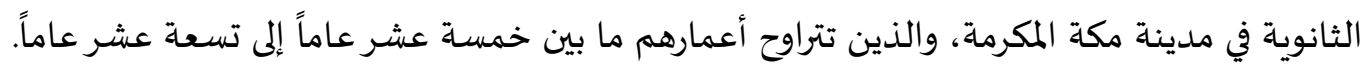

مصطلحات الدراسـة: -

O هي تقدير معالم الصعوبة والتمييز والتخمين لكل فقرة من فقرات الاختبار، وكذلك دالة معلومات الاختبار والخطأ المعياري في تقدير القدرة وفق نظرية الاستجابة للمفردة الاختبارية.

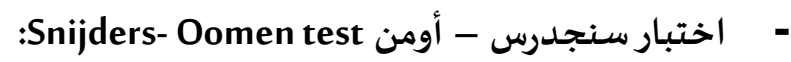

O هو اختبار يقيس ذكاء الأفراد الذين تتراوح أعمارهم بين ستة سنوات إلى أربعين سنة، والمقياس قابل للتطبيق

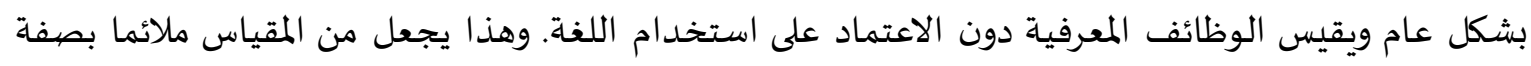

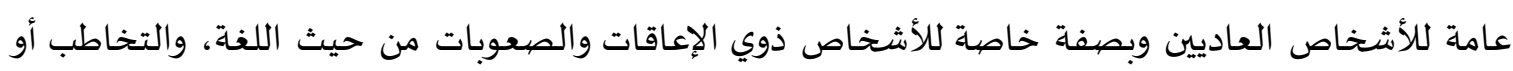

التواصل (Snijders, Tellegen \& Laros, 1988).

Non- verbal Intelligence: الذكاء غير اللفظي ) O يعرف بأنه: " الذكاء الذي يعبر عن المعلومات الذكائية التي لا تتطلب استخدام اللغة، ويمكن قياس الذكاء غير

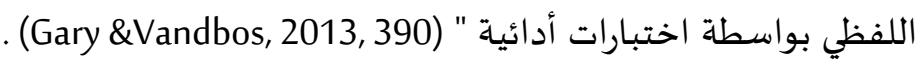

- نظرية الاستجابة للمفردة: Item Response Theory -

O هي نظرية سيكومترية معاصرة تحاول نمذجة العلاقة القائمة بين مستوى القدرة لدى الفرد التي يقيسها الاختبار

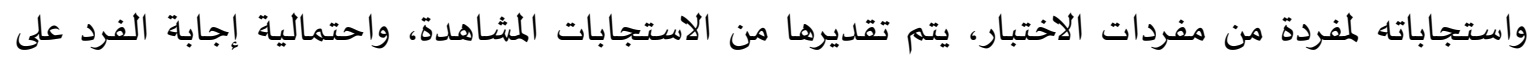
مفردات اختبارية مختلفة إجابة صحيحة (علام، 2005).

2- 2 - 2 أدبيات الدراسـة والدراسـات السابقة.

صهمت النسخة الأولى من اختبار SON لتقييم الأداء الإدراكي للأفراد (Snijders- Oomen, 1943). واعتمادا

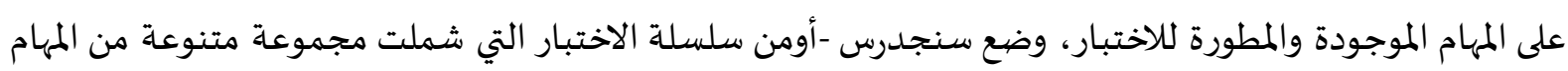




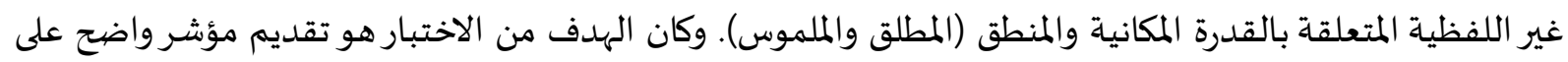

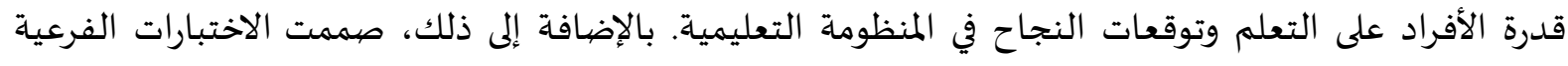

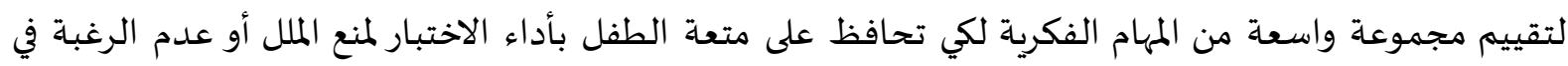

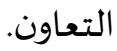

تم نشر النسخة الأولى للاختبار في عام 1958: 58 'SON Snijders \& Snijders- Oomen, 1958) Sم في هذه

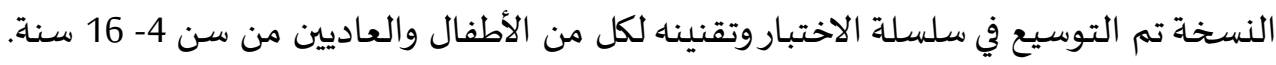

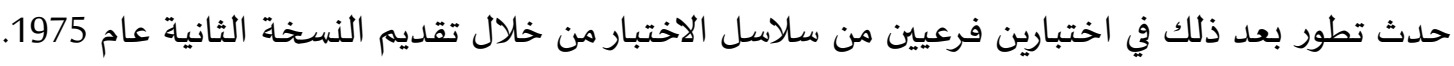

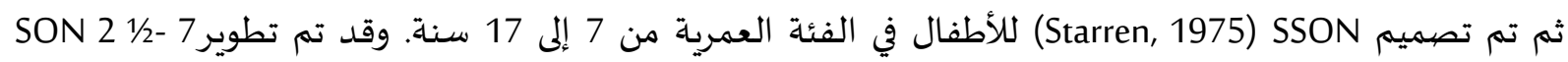

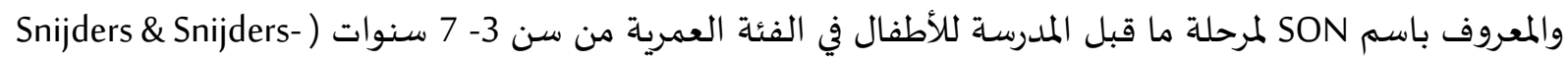

.(Oomen, 1975

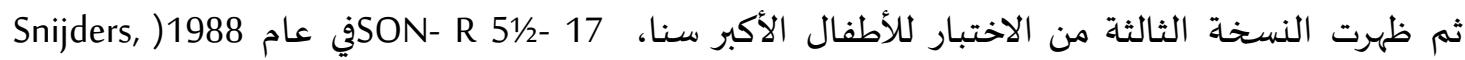
SON- هذا Sillegen \& Laros, 1988; Laros \& Tellegen, 1991; Tellegen \& Laros, 1993

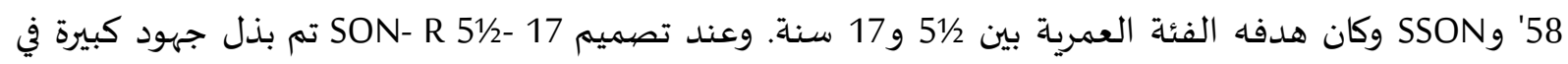

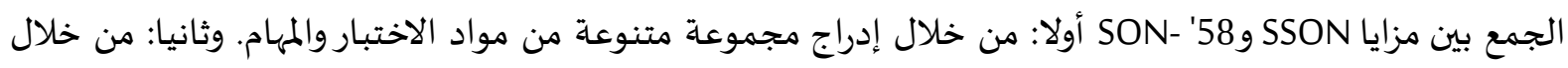

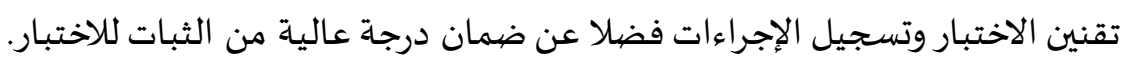

ثانياً - الدراسـات السابقة: أجريت العديد من الدراسات هدفت إلى التعرف على الخصائص السيكومترية لاختبار SON- R 6- 40 وكانت على النحو الآتي:

- أولها دراسة اجريت في الصين عام 2010، لقياس الذكاء غير اللفظي لعينة من 1600 فرد، \&u, Zhang, Du (Tellegen, 2011)

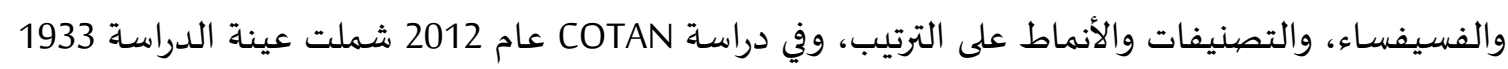

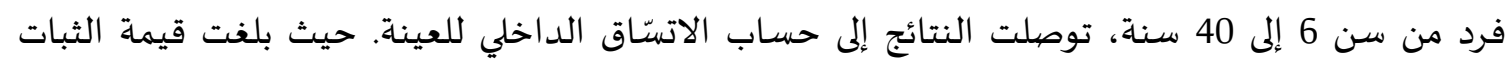
الكلي (ألفا- كرونباخ) للاختبار ككل 0.95، ولاخلاختبارات الفرعية بلغت

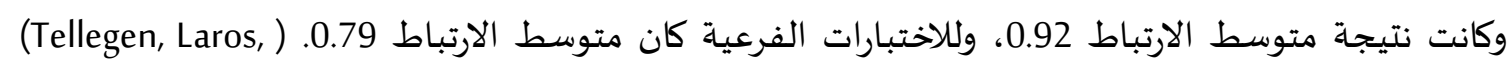
2014 وفي البرازيل دراسة (Laros, 2013) عام 2010 كانت لـ 44 طفلاً 23 من الذكور، و21 من الإناث تراوحت

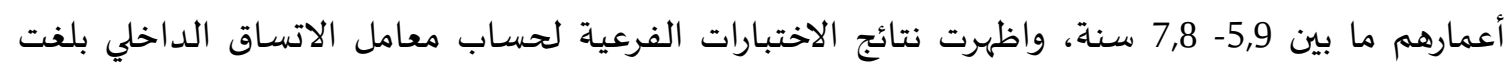
قيمته (0.92)، وقيمة معامل الثبات لجميع الاختبارات الفرعية بلغت (0.80)

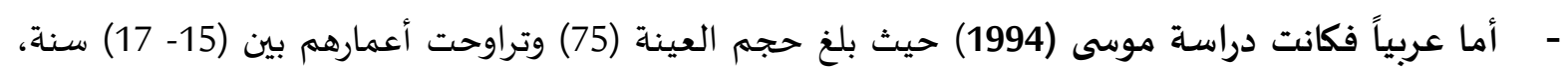

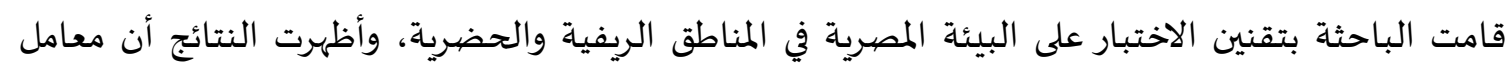
الثبات بطريقة التجزئة النصفية مقداره (0.79). - وأما في المملكة العربية السعودية أجريت دراسة صدئ مقديق (2007) وهدفت الدراسة إلى معرفة الفروق بين فاقدات السمع والعاديات في الأداء العقلي المعرفي، وتم حساب ثبات المربة الاختبار عن طريق استخدام التجزئة 
النصفية من خلال إيجاد قيمة معامل ثبات معادلة سبيرمان- بروان والتي اشارت إلى أن الاختبار يتمتع بثبات فوق المتوسط حيث بلغت قيمة معامل ثبات الاختبار ككل (0.87). وهدفت دراسة (الثبيتي، 2016) إلى تقنين الاختبار على طلاب المرحلة الثانوية في مدينة الطائف، حيث تم

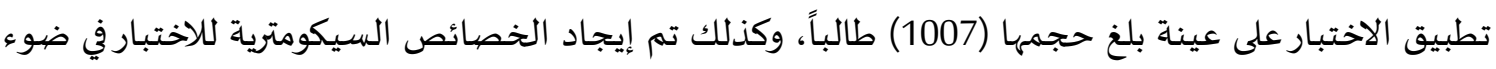

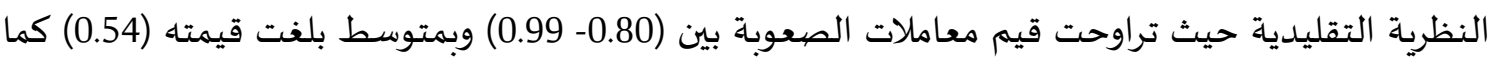

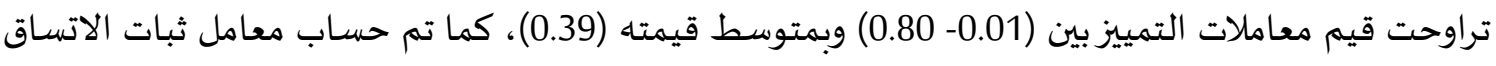

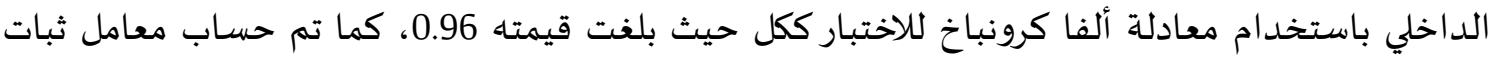
إعادة الاختبار على عينة جزئية بلغ حجمها 100طالب على مستولى معادئ الاختبار حيث بلغت قيمته (0.89)، وهي قيم مرتفعة تدل على ثبات الاختبار. وفي دراسة (الزهراني، 2016) هدفت إلى إيجاد الخصائص السيكومترية على طلاب المرحلة الثانوية في مكات

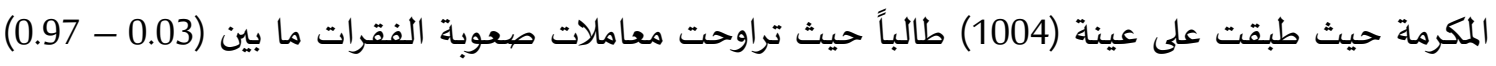

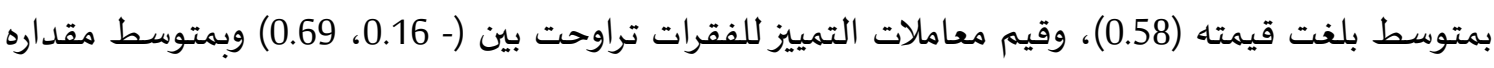

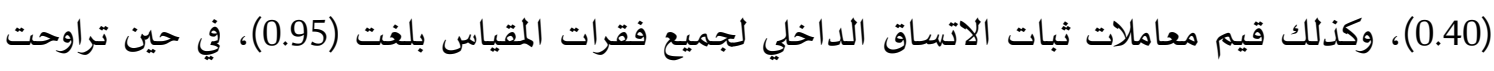

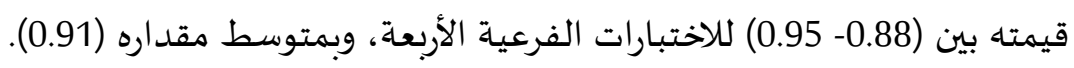

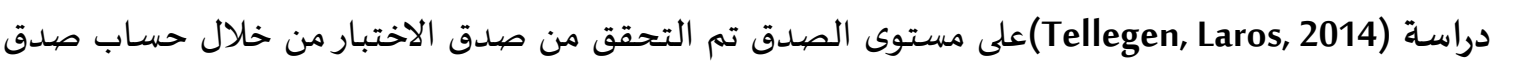

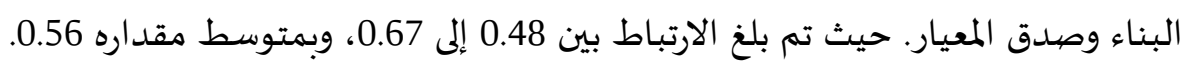

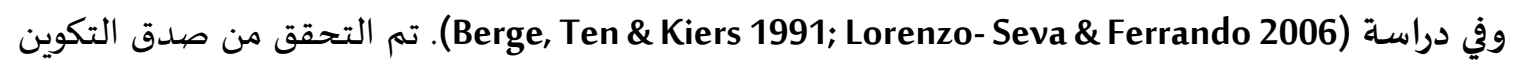
الفرضي حيث تم إجراء التحليل العاملي بهدف تحديد عدد الأبعاد حيث استخدام التحليل العاملي

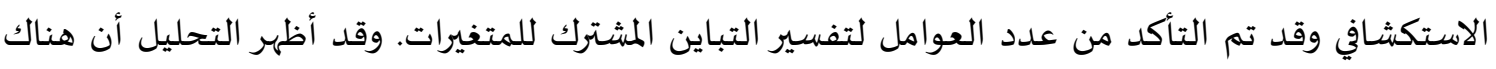

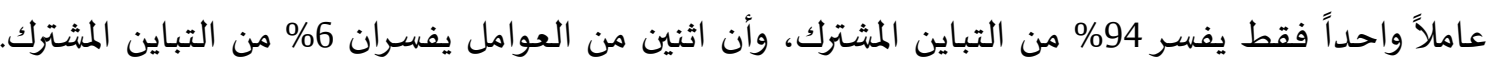

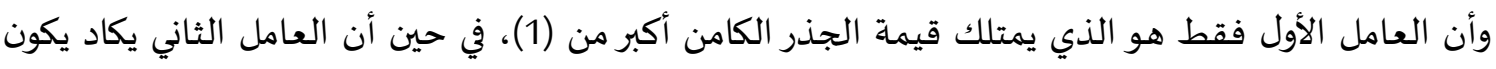

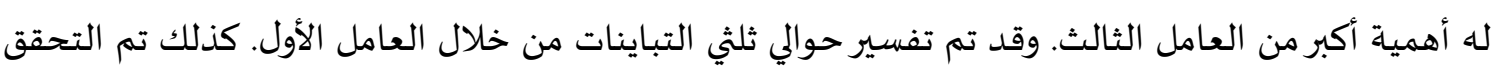

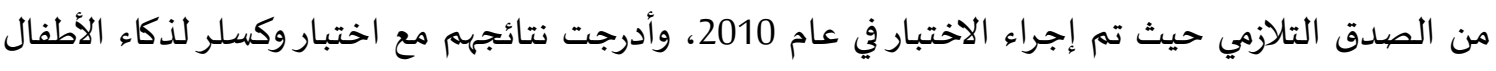

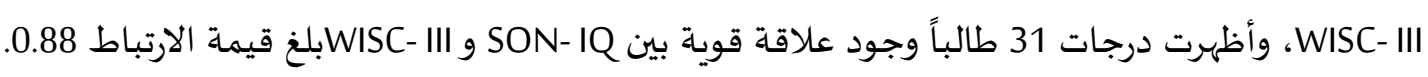

تعليق على الدراسـات السابقة: من خلال العرض السابق للدراسات السابقة التي أجريت على اختبار سنجدرس أومن والتي كانت في ضوء التهاب

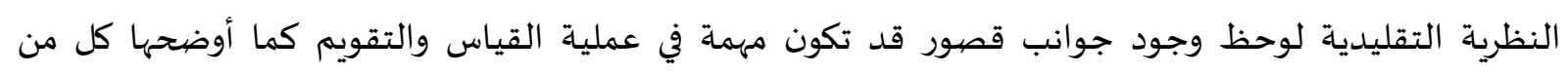
هامبلتون وسومناثان (Hambleton \& Swaminathan, 1985)، منها: 1- إن خصائص الفقرات مثل الصعوبة والتمييز، وخصيائص الاختبار مثل الثبات يعتمد على عينة الأفراد الذين يجري عليهم الاختبار. 2- لم تقدم النظرية التقليدية حلولاً للكثير من المشكلات المتعلقة بالاختبارات مثل تصميم الاختبار وتحيز الفقرات.

3- لم تأخذ النظرية التقليدية بعين الاعتبار استجابة الأفراد على فقرة معينة حيث تعتمد على الدرجة الكلية

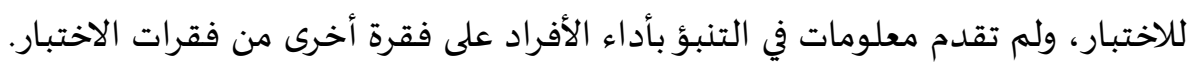


4- النظرية التقليدية تفترض تساوي تباين خطأ القياس لجميع المفحوصين. وتأثر خصائص فقرات الاختبار بقدرة

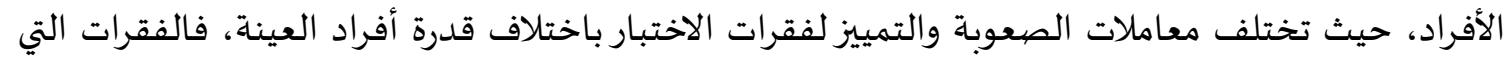

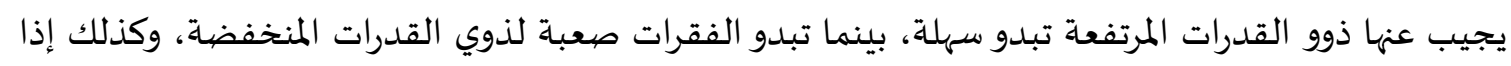

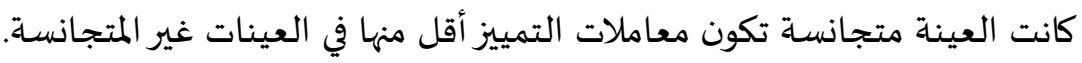

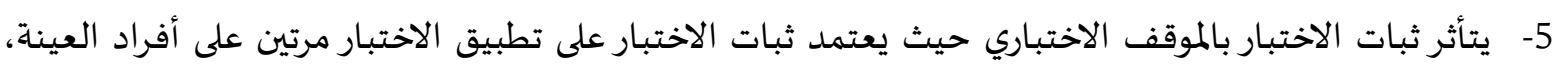

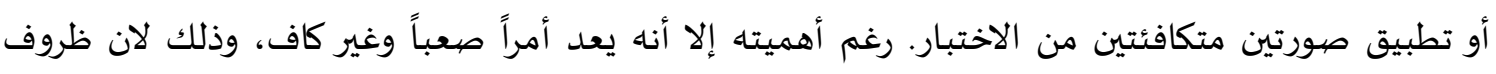

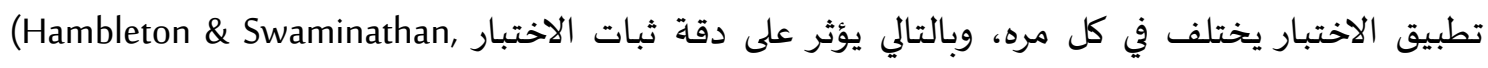

ونتيجة لجوانب النقد التي وجهت إلى نظرية القياس التقليدياة، قام علماء القياس بجهود بحثية لتطوير

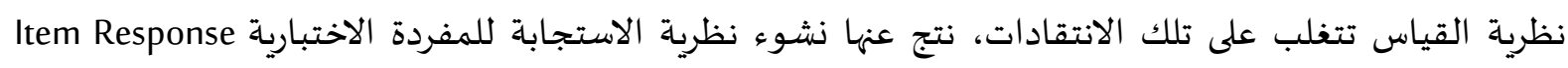

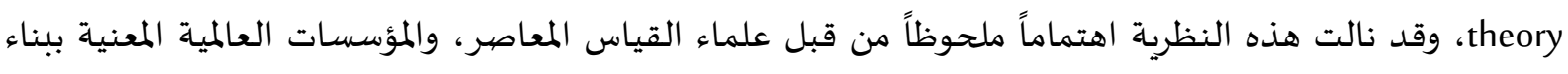
الاختبارات والمقاييس، حيث أصبحت تستخدم في بناء وتطوير الاختبارات النفسية والتربوية المختلفة.

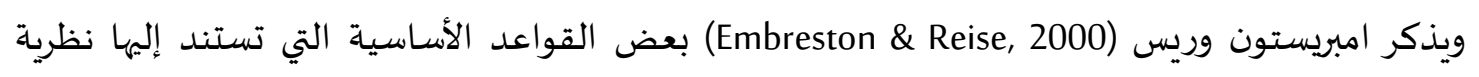
الاستجابة للفقرة (IRT) وهي ما يلي:

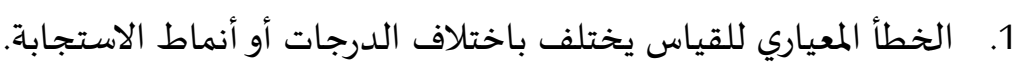
2. تقدير قدرة الأفراد يختلف تماماً عن تقدير معالم الفقرات.

3. يمكن الحصول على تقديرات غير متحيزة لخصائص الفقرة من عينات غير ممثلة من الأفراد.

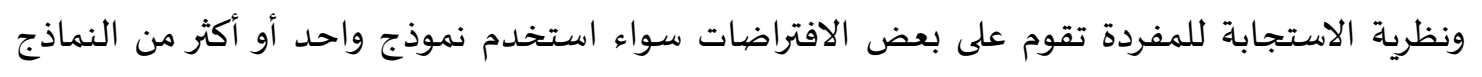

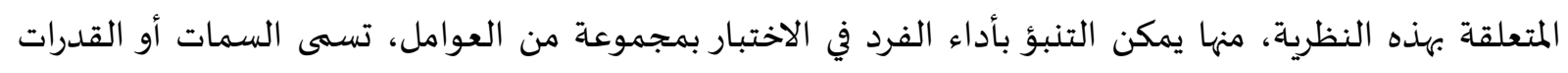

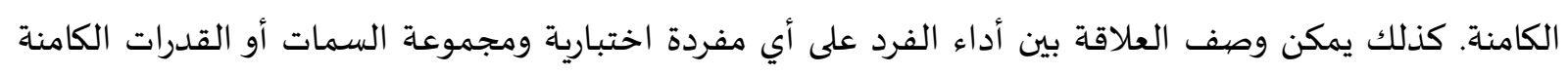

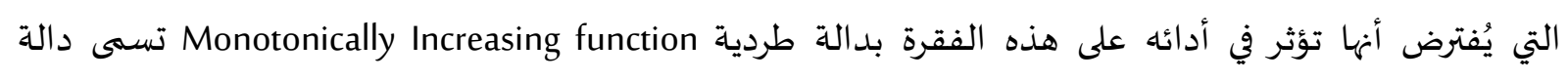

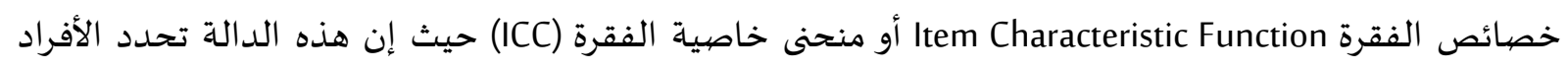

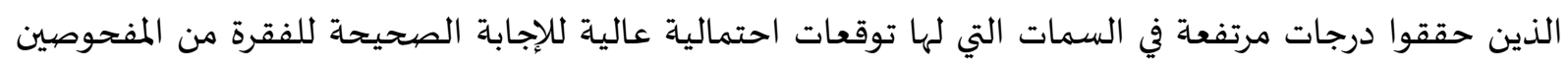

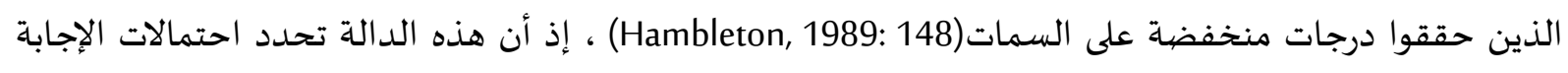

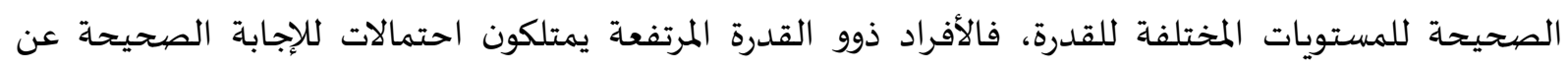

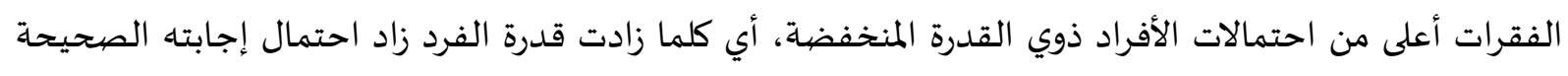

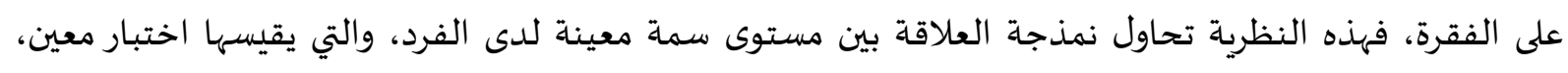

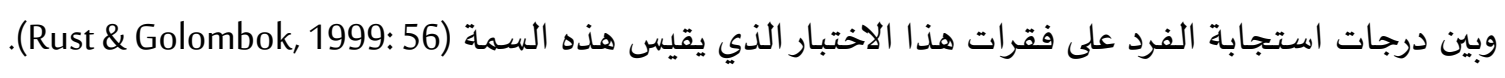

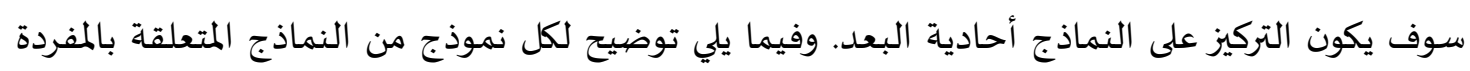

\section{ثنائية الاستجاباة. \\ 1- نموذج أحادي المعلم (نموذج راش).}

يعد أبسط نماذج الاستجابة للمفردة أحادية البعد. سُمي بنموذج راش المعلم نسبة لعالم الرياضيات الدنماركي

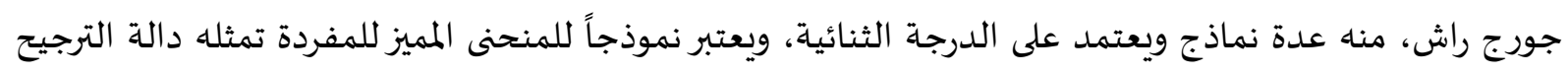

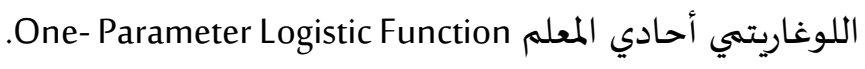




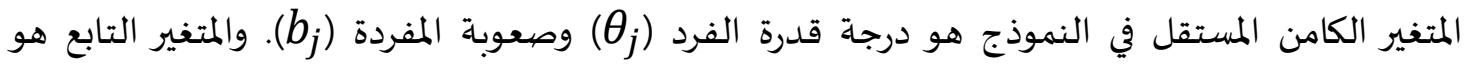

احتمالية الفرد (j) يجيب إجابة صحيحة على مفردة اختبارية (i). وفق المعادلة التالية:

$$
p_{i}(\theta)=\frac{e^{\theta_{j}-b_{i}}}{1+e^{\theta_{j}-b_{i}}}
$$

يفترض أن المفردات تختلف في معلمة الصعوبة فقط Item Difficulty Parameter. بمعنى أن جميع المفردات لها منحنيات مميزة على شكل حرف (S). أي تتساوى في تمييزها (لها نفس الميل)، والفرق بين نموذج راش ال

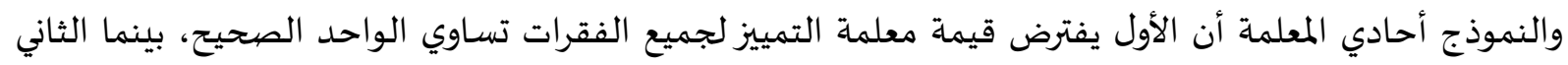
يفترض قيمة معلمة التمييز لجميع الفقرات متساوية وليس بالضرورة أن تكون واحد المعد صحيح.

$$
\text { 2- نموذج ثنائي المعلم (نموذج بيرنيوم). }
$$

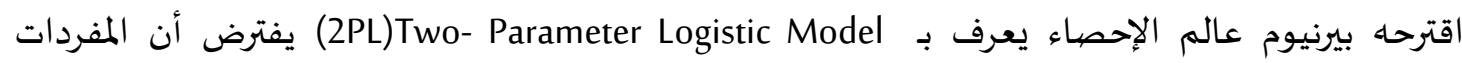

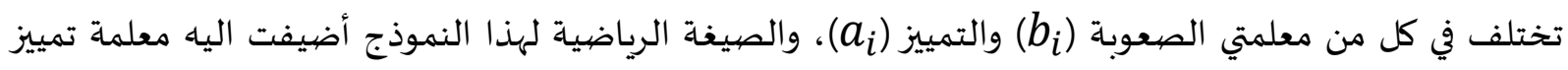

$$
p_{i}(\theta)=\frac{e^{a_{i}\left(\theta_{j}-b_{i}\right)}}{1+e^{a_{i}\left(\theta_{j}-b_{i}\right)}}
$$

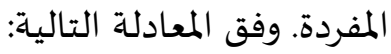

حيث إن تمييز المفردة ${ }^{\prime}$ الأ $a_{i}$ يضرب في الفرق بين مستوى القدرة وصعوبة المفردة، حيث له أثر كبير في الاحتمالات للمفردات الأكثر تمييزاً.

$$
\text { 3- نموذج ثلاثي المعلم (نموذج لورد). }
$$

الأفراد ذوي القدرة المخفضة ربما بمدا يلجؤون إلى التخمين العشوائي في مفردة اختيار من متعدد، وبالتالي

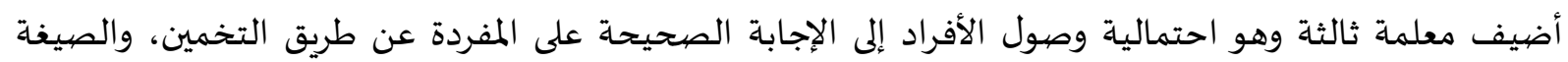

$$
p_{i}(\theta)=c_{i}+\left(1+c_{i}\right) \frac{e^{a_{i}\left(\theta_{j}-b_{i}\right)}}{1+e^{a_{i}\left(\theta_{j}-b_{i}\right)}}
$$

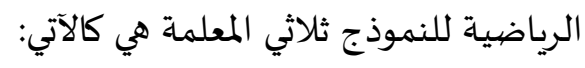

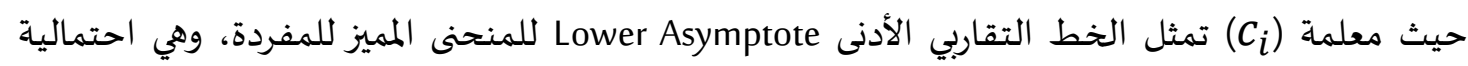

الإجابة الصحيحة للمفحوصين من ذوي القدرة المنخفضية.

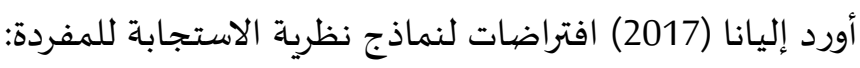

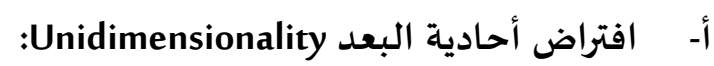

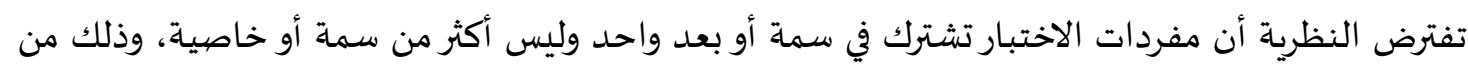

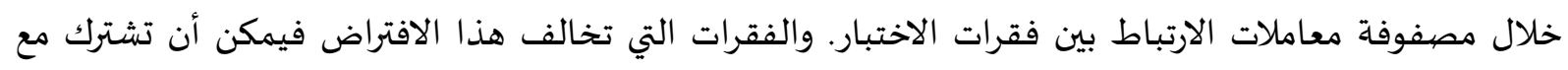

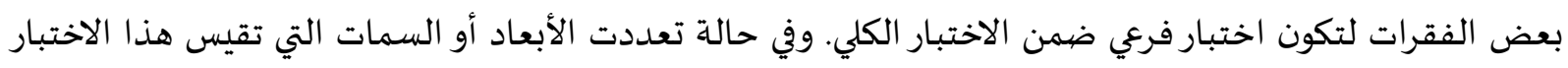

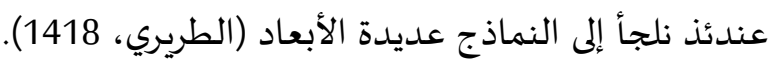

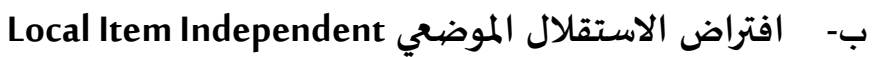
يشير إلى احتمالية الإجابة الصحيحة للمفردة الاختبارية. ويكون مستقل عن ناتج إجابته على أي مفردة

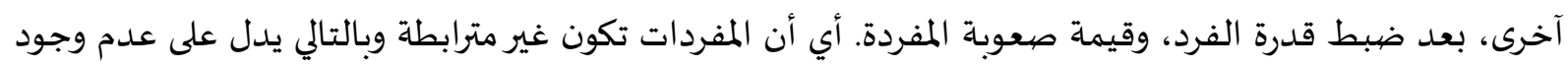

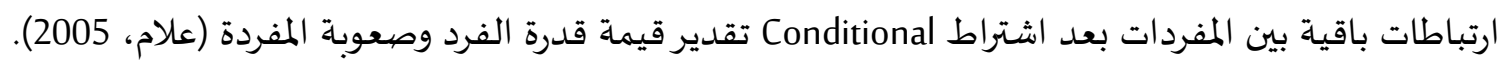


ويتحقق هذا الافتراض في النماذج ثنائية الاستجابة عندما تقيس جميع المفردات سمة واحدة أو قدرة

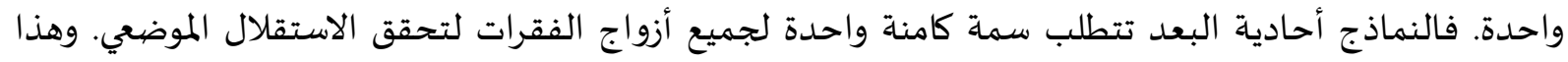

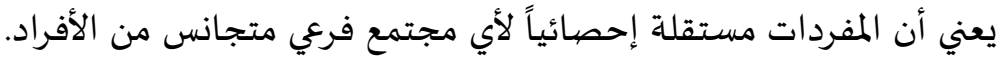
ج- المنحنى المميز للمفردة.

Logistic يفترض النموذج دالة مميزة خاصة لكل مفردة على شكل منحنى الترجيح اللوغاريتهي الاحتمالي يسمى بالمنحنى المميز للمفردة (ICC Curve

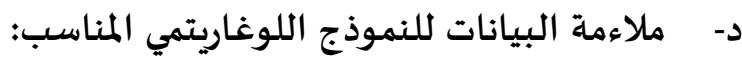

بعد التحقق من افتراضيتي أحادية البعد والاستقلال الموضعي في مصفوفية المنابت البيانات الاختبارية، يتم التوصل

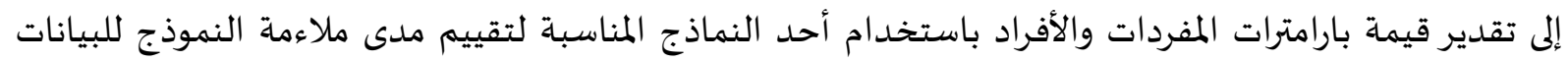
من خلال:

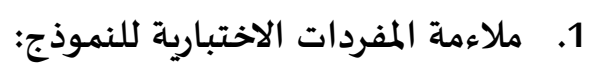

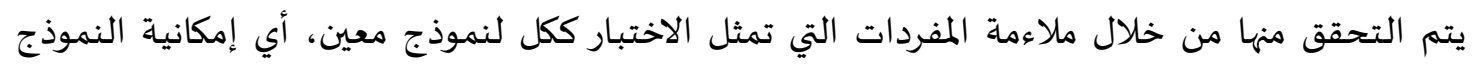

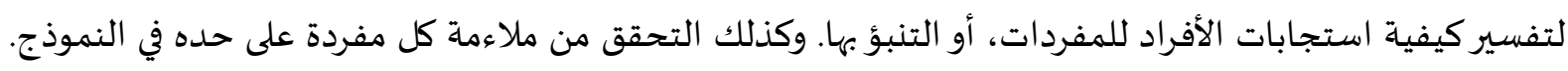

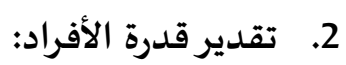

تعتمد احتمالية الاستجابة على مفردة اختبارية أحادية البعد على قدرة الفرد (ق) والمعالم المتعلقة بالمفردة،

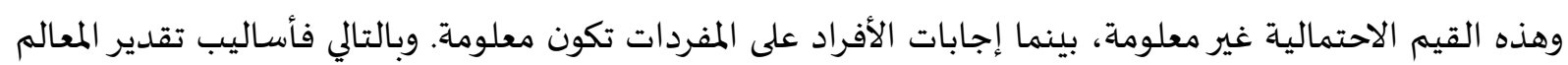

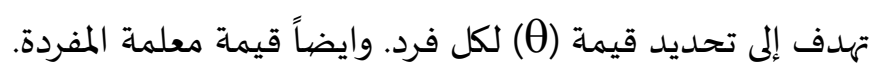
وتكون عادة الاستجابة على المفردة غير خطية Nonlinear حيث المتغير المستقل هو القدرة (ق). ويتم تقدير

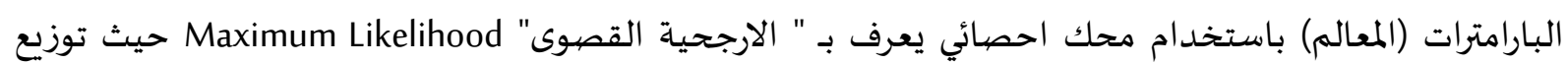
المعاينات Sampling Distribution يمكن تقديرها احصائياً في العينات الكبيرة. ومن أهم أساليب تقدير الارجية الارجحية

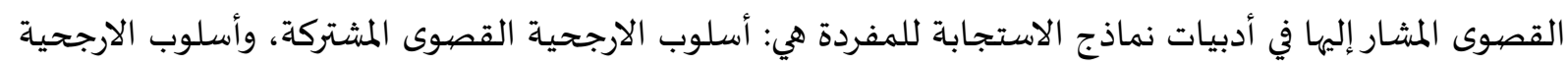

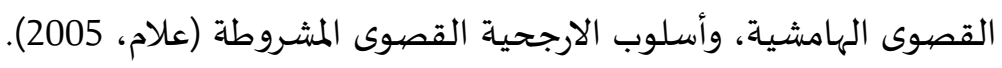

3- منهجية الدراسـة وإجراءاتها.

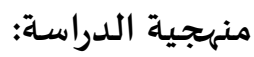
استخدم الباحث المنهج الوصفي لوصف الخصائص السيكومترية لاختبار سنجدرس أومن وفق نظرية الاستجابة للمفردة الاختبارية.

\section{مجتمع الدراسـة وعينتها:}

تمثل مجتمع الدراسة في طلاب المرحلة الثانوية في مدينة مكة المكرمة التابعين للإدارة العامة للتعليم بمنطقة مكة المكرمة. وقد تم اختيار عينة عشوائية بلغ عدد أفرادها (1100) طالب بطريقة العينة العشوائية

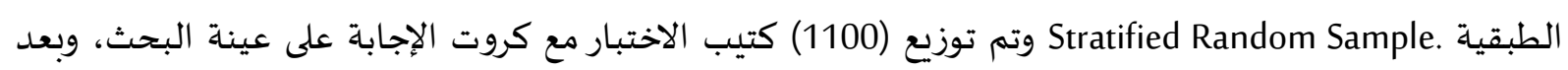

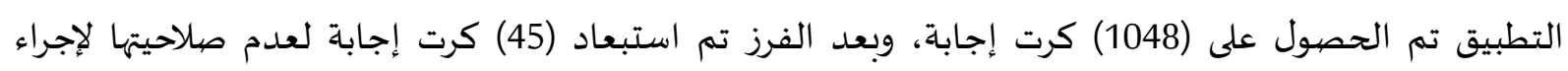

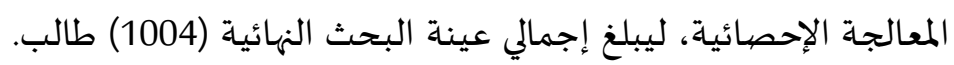


تم تطبيق الاختبار على العينة في دراسة سابقة للباحث (الزهراني، 2016) وفق الخطوات والإجراءات المتبعة فيها. وقد تم اعتماد البيانات المتحصل عليها من الدراسة السابقة لكون الاختبار يقيس الذكاء العام وانه يتسم

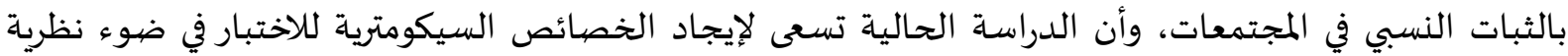
الاستجابة للمفردة الاختبارية.

ولتحديد أنسب نموذج من نماذج نظرية الاستجابة للمفردة الاختيارية أحادية البعد (الأحادي- الثنائي-

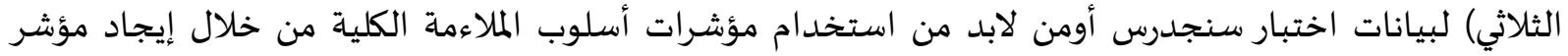

انحراف النموذج (2 LLH) -) لكل نموذج من النماذج الثلاثة باستخدام برمجية (Kumagai, 2017) Estimation

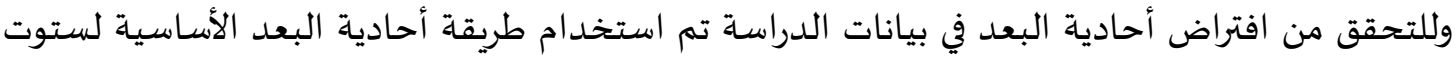
من خلال برمجية) DIMTEST 2.0 (stout, 2005) ، وطريقة تحليل البواقي في نماذج نظرية الاستجابة المفردة الاختبارية

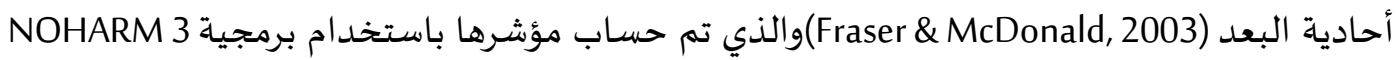

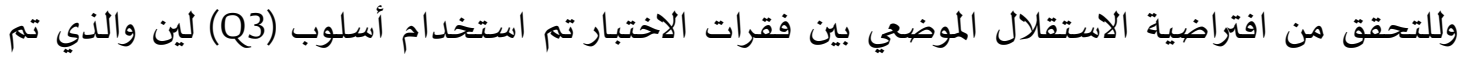
حسابه باستخدام برمجية LDID (Kim et al, 2005 ومن خلال استخدام برمجية eirt وذلك بعد معايرة البيانات باستخدام النموذج اللوغاريتهي ثنائي المعالم عن طريق برمجيه Excel لمؤشر X2.

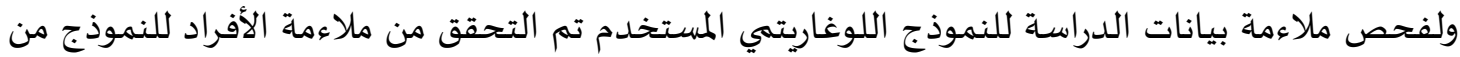
خلال حساب مؤشر الملاءمة Persons Fit لكل فرد من أفراد عينة الاختبار حيث يمثل معامل ملاءمة الأفراد للنموذج من خلال برمجية Easy Estimation. كذلك تم التحقق من الملاءمة الكلية للاختبار مع النموذج من خلال إيجاد

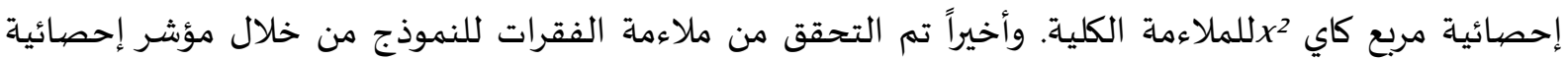

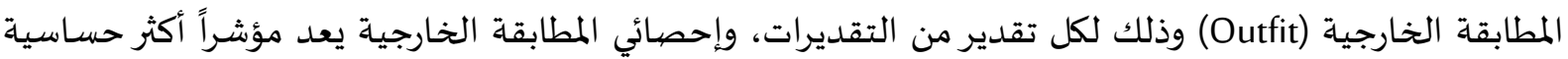

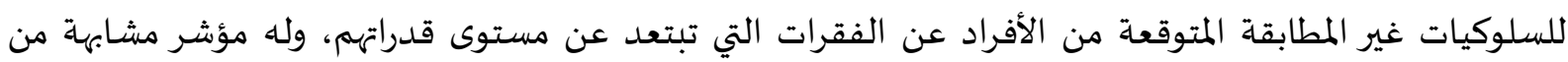

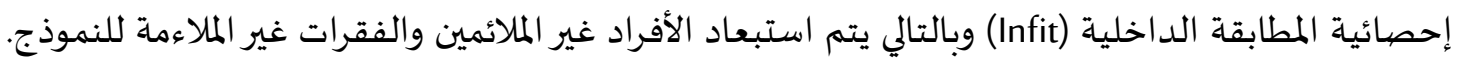

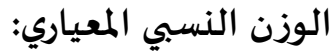

Maximum لإيجاد الخصائص السيكومترية للاختبار تم استخدام أسلوب تقدير الأرجحية القصوى Likelihood Estimation (MLE) معلمة صعوبة الفقرات والخطأ المعياري لتقديرها، وذلك لكل فقرة من فقرات الاختبار. والحكم على مستوى معات

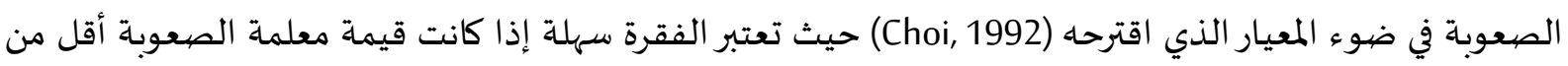

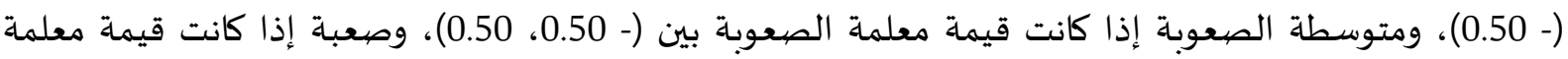

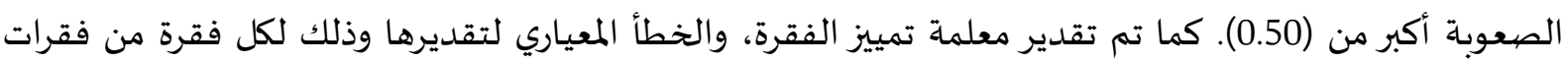

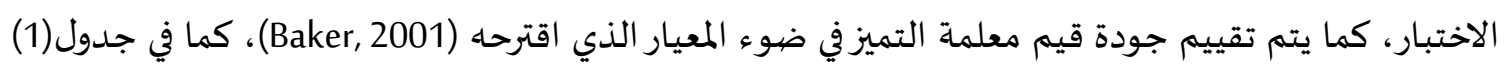
جدول (1) معيار بيكر لتقييم جودة معلمة تمييز الفقرات

\begin{tabular}{|c|c|c|c|c|c|c|c|}
\hline مثالي & مرتفع جداً & مرتفع & متوسط & منخفض & منخفض جداً & غير مميز & مستوى التميز \\
\hline$\infty$ & $1.70<$ & $1.69-1.35$ & $1.34-0.65$ & $0.64-0.35$ & $0.34-0.01$ & صفر & قيمة معلمة التميز \\
\hline
\end{tabular}


أيضاً تم تقدير قيم دالة المعلومات التي يقدمها الاختبار عند مستويات مختارة من القدرة لإيجاد قدرات

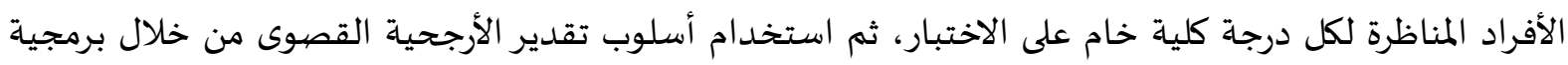
Easy Estimation

1- المعالجات الإحصائية:

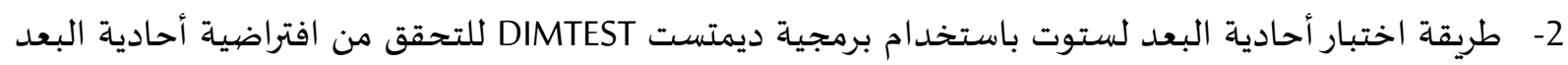
والاستقلال الموضعي. 3- طريقة تحليل البواقي باستخدام برمجية نوهارم NOHARM.

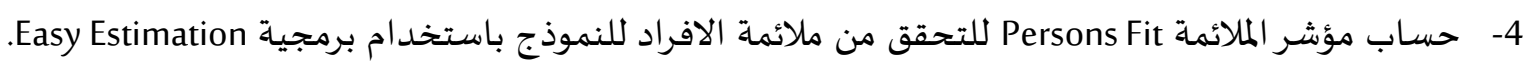

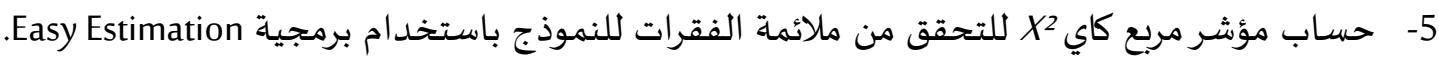
4- نتائج الدراسة ومناقشتها.

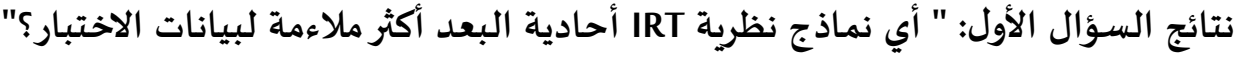

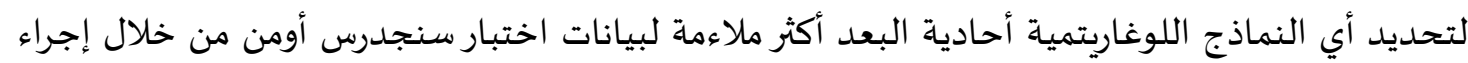

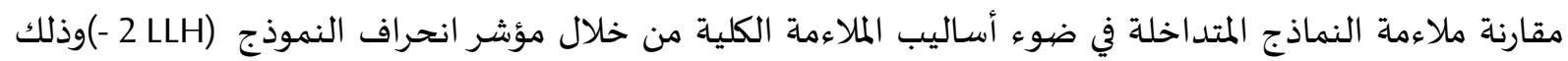
بغرض اختبار الفرضيتين الصفرية الآتية: الفرضية الأولى: إن إضافة معلمة التمييز إلى النموذج الأحادي المعلمة لا يؤدي إلى تحسن دال الإنة إحصائياً في

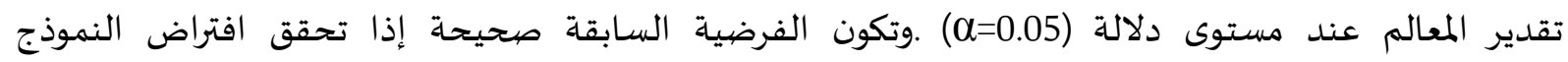

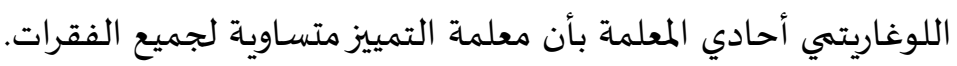

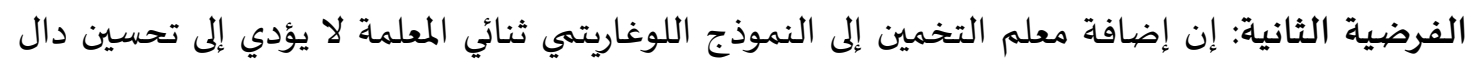

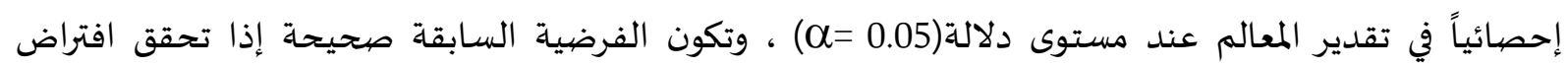

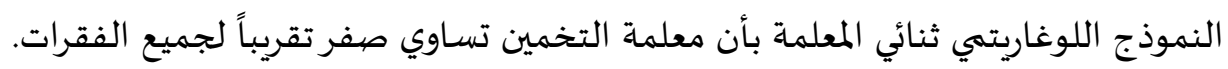

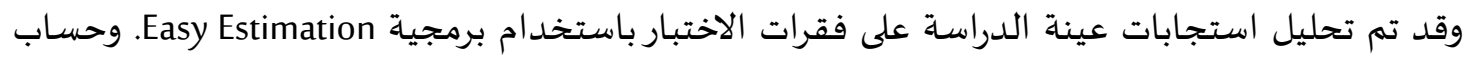
إحصائي مؤشر انحراف النموذج (2LHH 2 -) لكل نموذج من النماذج اللوغاريتمية الثلاثة، ولاختبار الفرضية الأولى تم إيجاد الفرق بين قيمتي (2LH 2 -) للنموذجين أحادي المعلمة وثنائي المعالم ( 33018 -31884 =

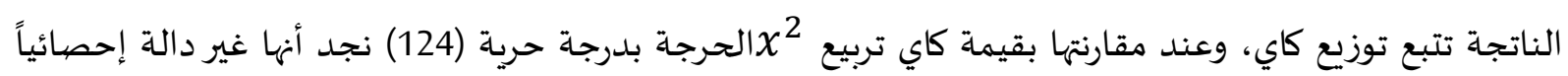

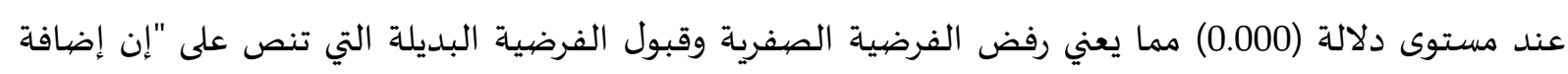

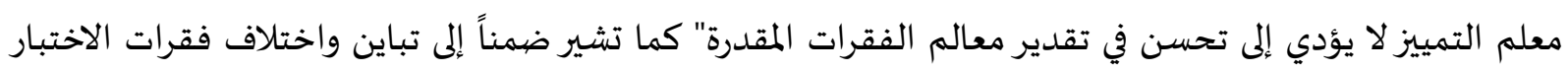

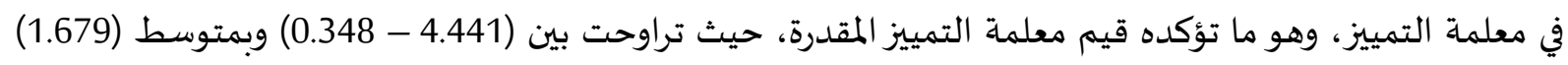

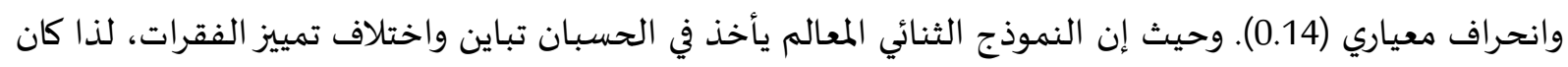
هو النموذج الأكثر ملاءمة لبيانات الاختبار من النموذج أحادي إنهودي المعلمة. ولاختبار الفرضية الثانية تم إيجاد الفرق بين قيمتي (2LLH -) للنموذجين ثنائي وثلاثي المعالم (31884-

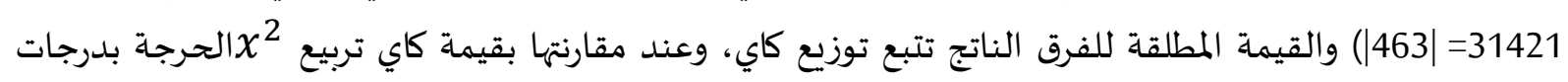


حرية (124) نجد أهها دالة إحصائياً عند مستوى دلالة (0.000)، مما يعني رفض الفرضية الصفرية التي تنص على

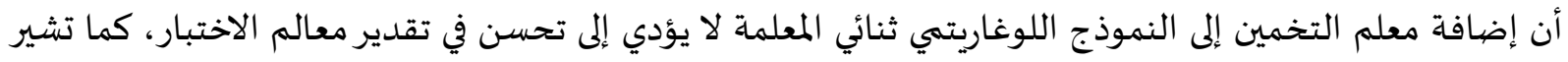

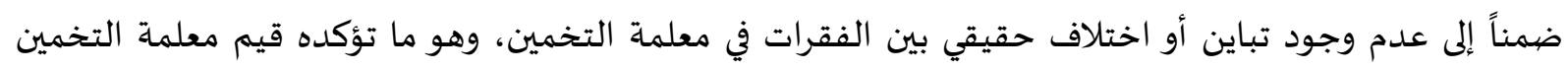

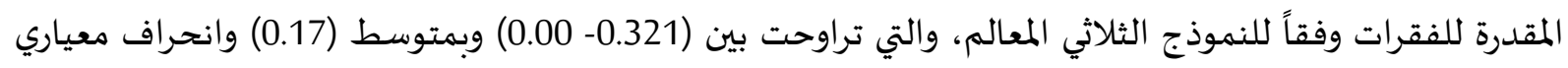

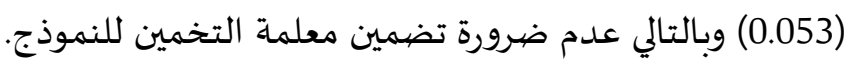

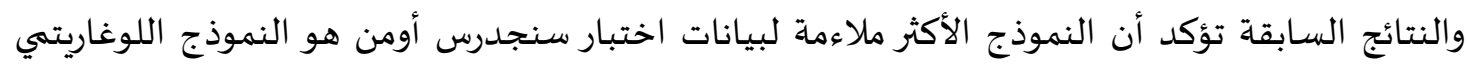
ثنائي المعالم (2PLM) وفي هذا إجابة على السؤال الأول من تساؤلات الدراسة.

نتائج السؤال الثاني: هل تتحقق افتراضيات IRT في البيانات وفق النموذج اللوغارتيمي المناسب؟

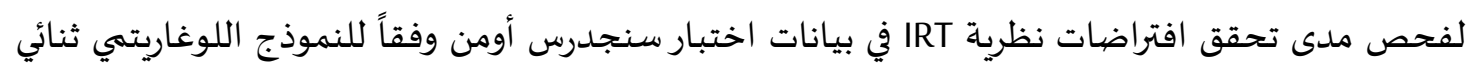

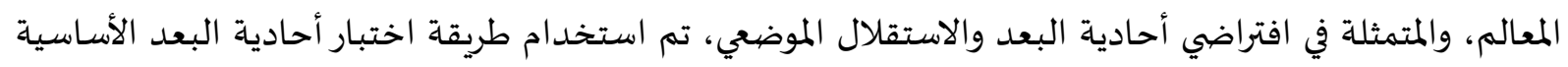

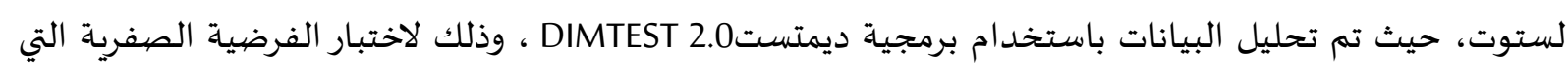

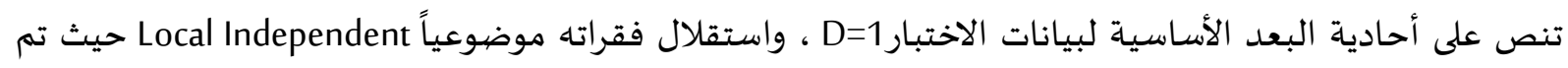

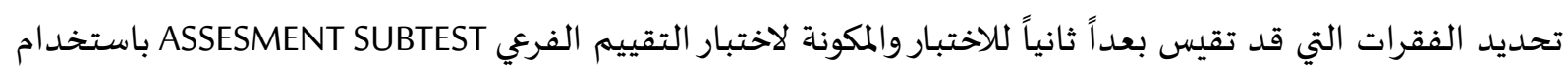

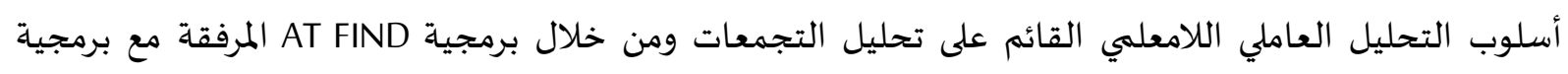

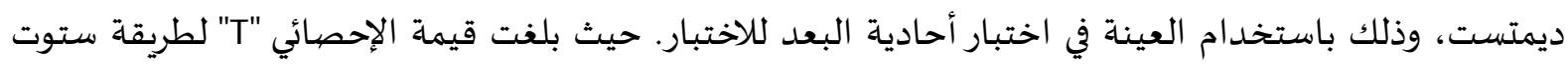

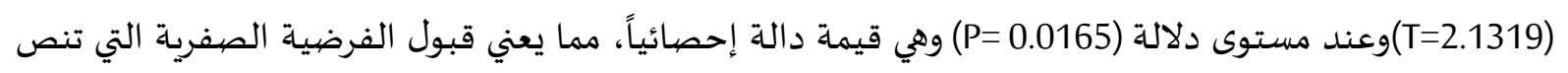

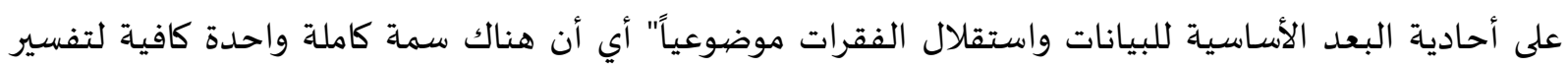
تباين أداء الأفراد على الاختبار. كما تم تمثيل الجذور الكامنة للعوامل جميعها بيانياً لنموذج الاختبار عن طريق الاختبار الفيار الفحص البياني Scree Plot

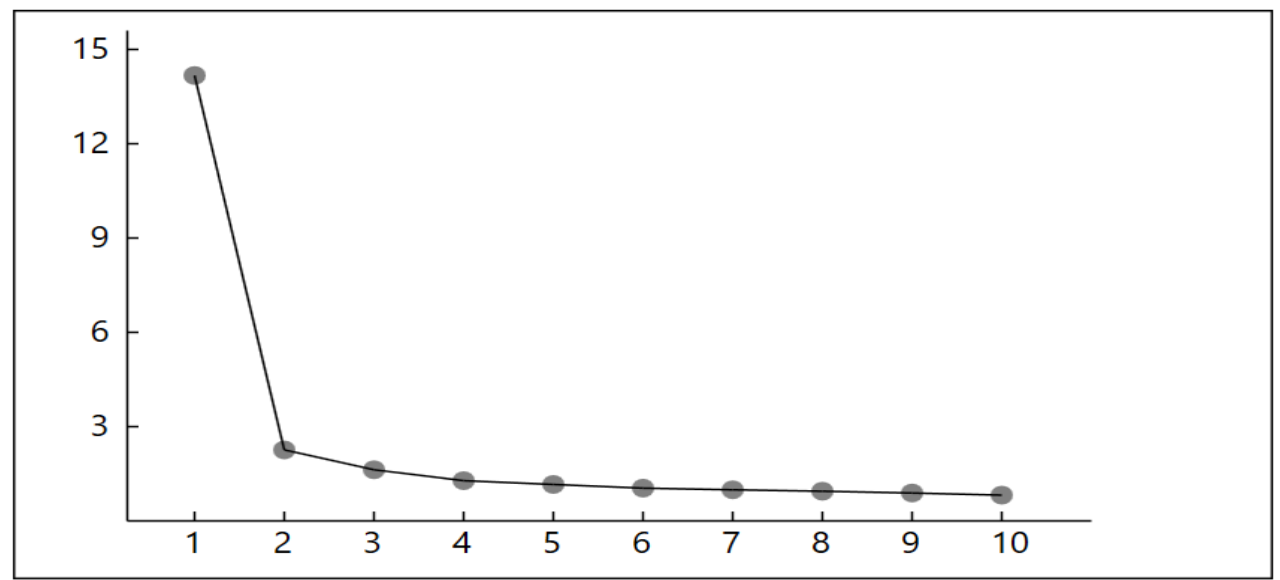

شكل (1) التمثيل البياني لقيم الجذور الكامنة للعوامل المكونة لنموذج الاختبار

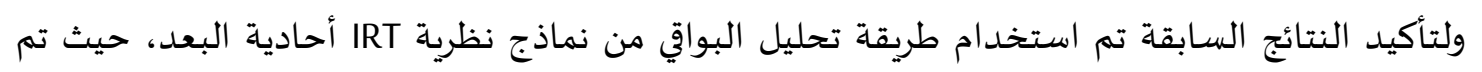

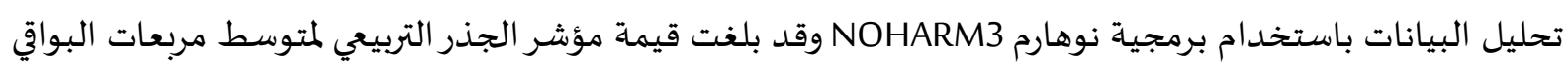

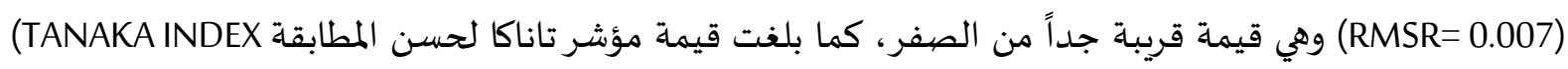

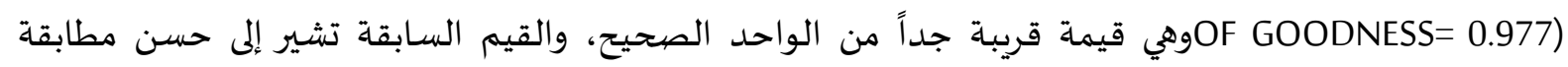


البيانات للنموذج أحادية البعد، مما يدل على تحقق افتراض أحادية البعد في بيانات الدارسة. والنتائج السابقة

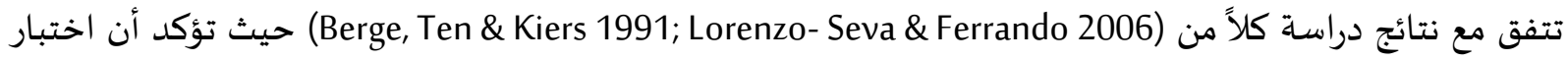
سنجدرس أومن يقيس عامل عام واحد، وهذا يتوافق مع الإطار النظري للاختبار.

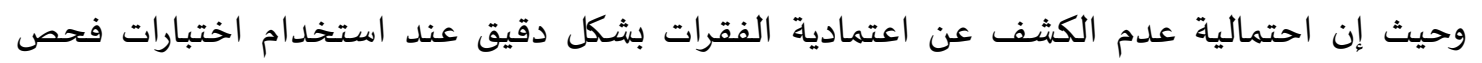

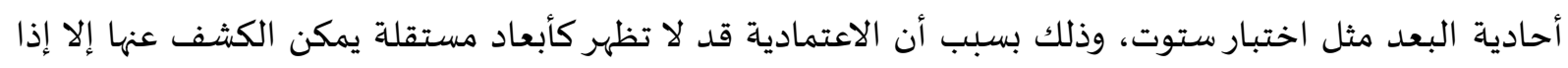

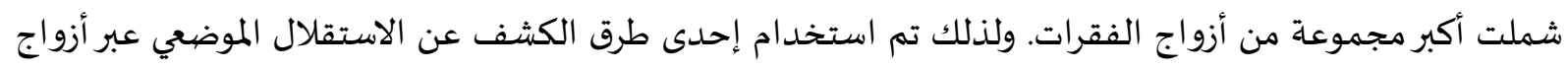

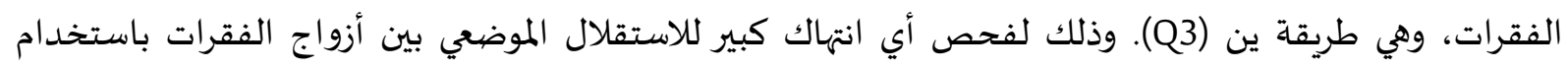

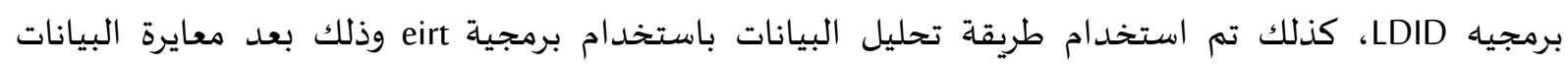
باستخدام النموذج اللوغاريتمي ثنائي المعالم وعن طريق برمجيا Excel حيث تم إيجاد قيمة

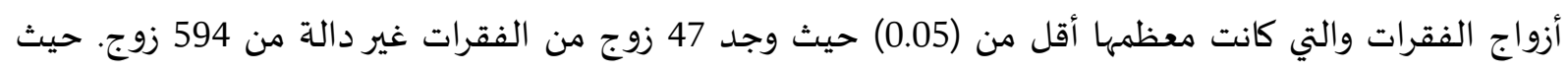

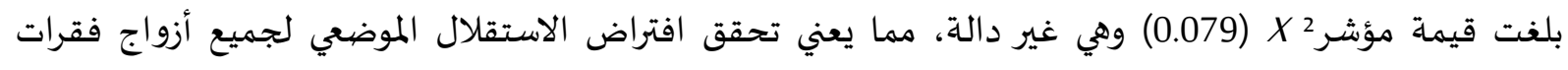

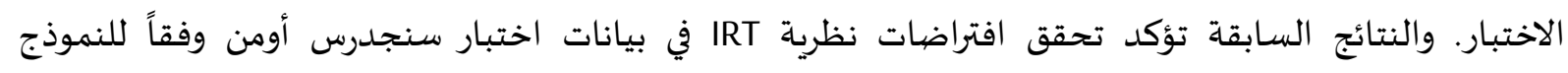

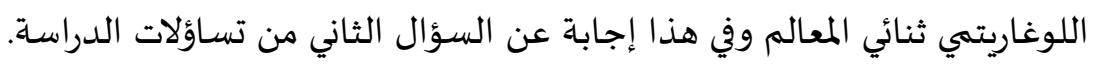

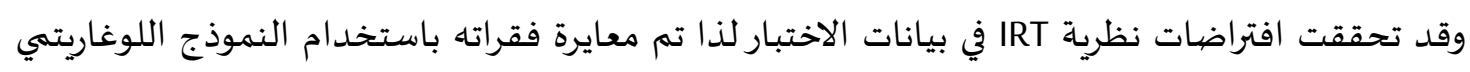

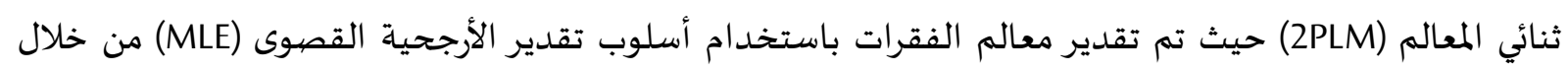
برمجية Easy Estimation وقد تم إيجاد القيم التقديرية الههائية لمعالم الفقرات والأفراد، وأخطائها المعيارية بعد المعدية

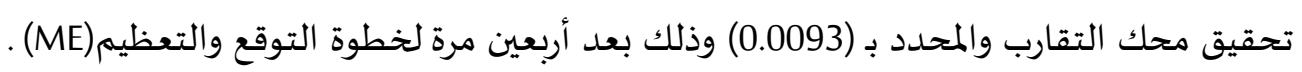

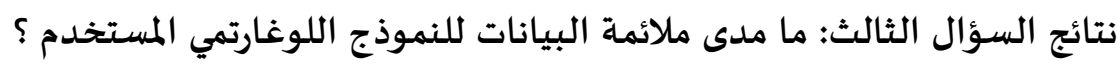

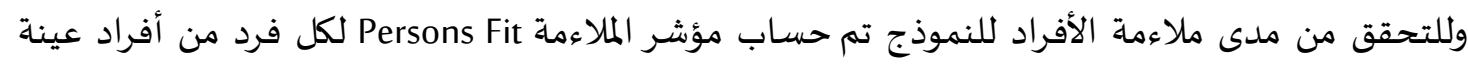

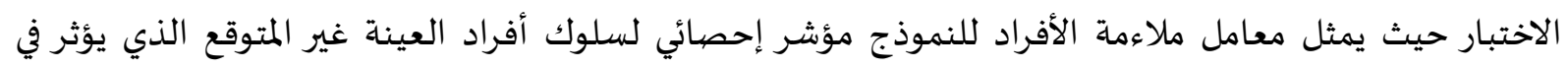

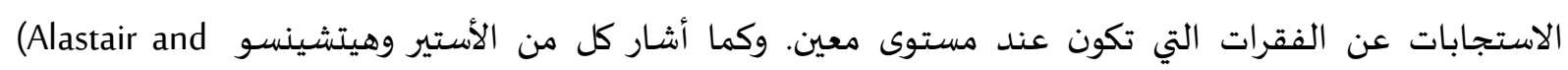

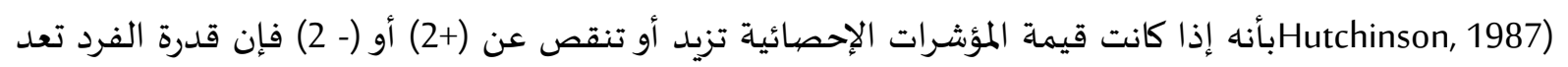
غير متطابقة مع قدرات مجموعة الأفراد، وبناء على ذلك كانت جميع قيم المؤشر موجبة ما عانس إندا (30) ثلاثون فرداً

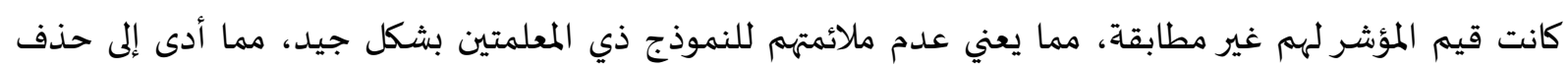
استجابات هؤلاء الأفراد واستبعادهم من عينة الدراسة ليصبح عدد ألمون أفراد العينة بعد الاستبعاد (947) فرداً.

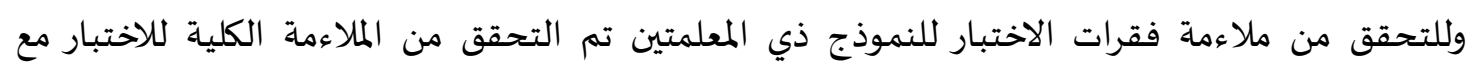

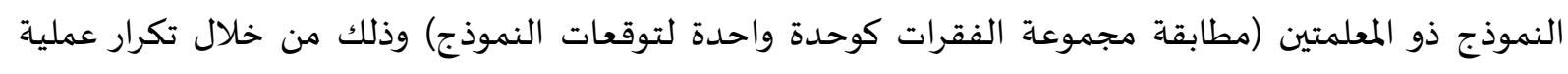

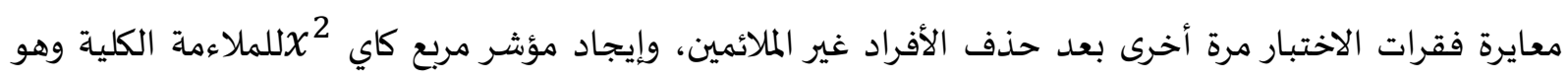

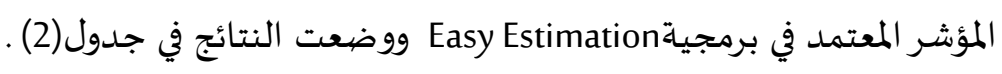

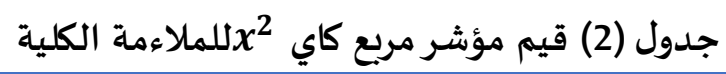

\begin{tabular}{|c|c|c|c|c|}
\hline مستوى الدلالة p & df درجات الحرية & قيمة كاي تربيع $x^{2}$ & عدد الفقرات & الاختبار \\
\hline 1.000 & 1612 & 3403.131 & 124 & كامل الاختبار \\
\hline
\end{tabular}

يتضح من الجدول أن قيمة مربع كاي للملاءمة الكلية بلغت (3403.131) غير دالة إحصائياً عند مستوى دلالة (0.05) مما يعني أن هنالك ملاءمة كلية للاختبار للنموذج اللوغاريتهي ثنائي المعلمة. 
كما تم التحقق من ملاءمة الفقرات للنموذج كل على حدة من خلال Test of fit اختبار حسن المطابقة

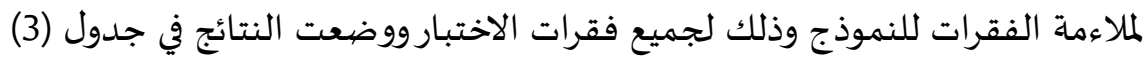

جدول (3) قيم إحصائي المطابقة Test of fit لملاءمة فقرات الاختبار للنموذج اللوغاريتمي ثنائي المعالم(2 PLM)

\begin{tabular}{|c|c|c|c|c|c|c|c|c|c|}
\hline المعياري له الهأ & $\begin{array}{l}\text { Infit } \\
\text { التقاربك }\end{array}$ & المعياري له الخطأ & $\begin{array}{l}\text { Out fit } \\
\text { التباعدي }\end{array}$ & $\overline{\overline{7}}$ & الملهياري الهي & $\begin{array}{c}\text { Infit } \\
\text { المحكك }\end{array}$ & المعياري له الخهأ & $\begin{array}{l}\text { Out fit } \\
\text { التباعدي }\end{array}$ & \\
\hline-0.00992 & 0.99933 & -0.05425 & 0.99758 & 32 & -0.22295 & 0.97834 & 5.97363 & 1.28373 & 1 \\
\hline-0.03649 & 0.9991 & -0.05992 & 0.99733 & 33 & 0.05492 & 1.00201 & 3.17319 & 1.1466 & 2 \\
\hline-0.23217 & 0.99522 & 0.0833 & 1.00372 & 34 & 0.03134 & 1.00057 & -0.87215 & 0.96144 & 3 \\
\hline-0.02503 & 0.99924 & -0.03944 & 0.99824 & 35 & -0.2527 & 0.98221 & 1.94425 & 1.08868 & 4 \\
\hline-1.06193 & 0.90628 & 17.45628 & 1.91125 & 36 & 0.18462 & 1.00652 & -1.56015 & 0.93156 & 5 \\
\hline-1.05449 & 0.91167 & 18.27662 & 1.95955 & 37 & -0.06841 & 0.9982 & 0.13055 & 1.00584 & 6 \\
\hline-1.62518 & 0.87269 & 110.56153 & 8.70969 & 38 & -0.20364 & 0.99421 & 0.86015 & 1.03878 & 7 \\
\hline-1.22288 & 0.89698 & 121.67587 & 9.6045 & 39 & -0.17188 & 0.99581 & 0.02167 & 1.00097 & 8 \\
\hline-1.76433 & 0.85696 & 273.2571 & 0.29971 & 40 & -0.18639 & 0.99575 & 0.05745 & 1.00257 & 9 \\
\hline 0.18029 & 1.01266 & -12.84716 & 0.51542 & 41 & -0.10496 & 0.9977 & -0.02388 & 0.99893 & 10 \\
\hline-0.67129 & 0.93528 & 33.66369 & 2.93109 & 42 & -0.05492 & 0.9975 & 0.00039 & 1.00002 & 11 \\
\hline-1.37901 & 0.88314 & 319.02418 & 0.22497 & 43 & -0.87486 & 0.9309 & 63.24753 & 0.03262 & 12 \\
\hline-0.5983 & 0.9408 & -10.35153 & 0.59489 & 44 & -0.09544 & 0.99068 & -9.09169 & 0.63779 & 13 \\
\hline 0.10478 & 1.00662 & - 14.09191 & 0.47852 & 45 & -0.21274 & 0.98316 & 19.27762 & 2.01904 & 14 \\
\hline-0.78471 & 0.92031 & 25.67185 & 2.41219 & 46 & -0.50553 & 0.96623 & 16.97136 & 1.88289 & 15 \\
\hline-0.56257 & 0.94644 & -5.45721 & 0.77174 & 47 & -0.57944 & 0.97156 & 4.66871 & 1.21896 & 16 \\
\hline-1.77837 & 0.86864 & 309.67436 & 0.42108 & 48 & -0.32389 & 0.98509 & -0.04669 & 0.99792 & 17 \\
\hline-1.20804 & 0.8988 & 102.05764 & 1.0313 & 49 & 0.00698 & 0.99989 & -0.20037 & 0.99107 & 18 \\
\hline-1.36194 & 0.90503 & 20.89584 & 2.11645 & 50 & -0.21927 & 0.99291 & 0.50832 & 1.02283 & 19 \\
\hline-0.95053 & 0.91219 & 29.96374 & 2.68744 & 51 & 0.00789 & 1.00002 & -0.08737 & 0.9961 & 20 \\
\hline-1.57163 & 0.87976 & 113.1242 & 0.91523 & 52 & -0.13865 & 0.99654 & 0.03083 & 1.00138 & 21 \\
\hline-1.49523 & 0.87507 & 228.94581 & 0.52763 & 53 & -0.09064 & 0.99748 & -0.05731 & 0.99744 & 22 \\
\hline-1.71657 & 0.84343 & 51.69498 & 0.18525 & 54 & -0.05845 & 0.99785 & 0.00473 & 1.00021 & 23 \\
\hline-1.22078 & 0.90198 & 196.89834 & 0.82328 & 55 & -0.01035 & 0.99703 & -3.90528 & 0.83343 & 24 \\
\hline-0.2639 & 0.98688 & 0.76546 & 1.03447 & 56 & 0.17194 & 1.01107 & -10.06004 & 0.60465 & 25 \\
\hline-0.38063 & 0.9893 & 0.80742 & 1.03638 & 57 & 0.02317 & 0.99987 & -9.65635 & 0.61833 & 26 \\
\hline-0.84378 & 0.93275 & 0.26276 & 1.01177 & 58 & 0.12856 & 1.00799 & -10.63663 & 0.58544 & 27 \\
\hline-0.94389 & 0.93922 & 13.46719 & 1.68247 & 59 & -0.2366 & 0.98693 & -0.56802 & 0.9748 & 28 \\
\hline-0.6344 & 0.95165 & 10.68852 & 1.52958 & 60 & -0.5884 & 0.97906 & 3.25879 & 1.15068 & 29 \\
\hline-1.56573 & 0.90021 & 26.30679 & 2.45237 & 61 & -0.65067 & 0.97113 & 4.14613 & 1.19344 & 30 \\
\hline-0.24454 & 0.99086 & 0.90004 & 1.04059 & 62 & 0.05445 & 1.00091 & -0.00904 & 0.9996 & 31 \\
\hline
\end{tabular}




\begin{tabular}{|c|c|c|c|c|c|c|c|c|c|}
\hline المعياري له الهطأ & $\begin{array}{l}\text { Infit } \\
\text { التماربي }\end{array}$ & المعياري له اله & $\begin{array}{l}\text { Out fit } \\
\text { التباعديك }\end{array}$ & 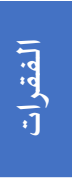 & المعياري لهأ & $\begin{array}{l}\text { Infit } \\
\text { التقاربك }\end{array}$ & المياري الهياري & $\begin{array}{l}\text { Out fit } \\
\text { التباعدي }\end{array}$ & 高 \\
\hline-0.023 & 0.99829 & -0.26899 & 0.98802 & 94 & -0.55809 & 0.97993 & 1.26273 & 1.05717 & 63 \\
\hline-0.3563 & 0.98071 & 0.59976 & 1.02696 & 95 & -0.14931 & 0.99643 & 0.13556 & 1.00606 & 64 \\
\hline-0.09118 & 0.99369 & -0.61786 & 0.9726 & 96 & -0.3138 & 0.98711 & 0.37463 & 1.0168 & 65 \\
\hline 0.09414 & 1.00403 & -0.67776 & 0.96997 & 97 & -0.01351 & 0.9996 & -0.06836 & 0.99695 & 66 \\
\hline 0.12107 & 1.00653 & -1.36145 & 0.94014 & 98 & 0.00981 & 0.99992 & -0.04013 & 0.99821 & 67 \\
\hline 0.02583 & 0.99455 & 5.90411 & 1.28024 & 99 & -0.02105 & 0.99921 & -0.23329 & 0.98961 & 68 \\
\hline-0.04212 & 0.99305 & -0.46391 & 0.97939 & 100 & -0.00186 & 0.99935 & -0.37466 & 0.98334 & 69 \\
\hline 0.07214 & 1.00327 & -0.96452 & 0.9574 & 101 & -0.09916 & 0.99509 & -0.12314 & 0.99451 & 70 \\
\hline 0.09855 & 1.0045 & -2.11373 & 0.90787 & 102 & 0.0751 & 1.00233 & -0.47439 & 0.97893 & 71 \\
\hline 0.48477 & 1.02291 & -4.08698 & 0.82607 & 103 & -0.22019 & 0.99252 & 0.0662 & 1.00296 & 72 \\
\hline 0.38237 & 1.01236 & -2.46709 & 0.89292 & 104 & 0.09151 & 1.00276 & -0.50912 & 0.9774 & 73 \\
\hline-1.18321 & 0.95725 & 2.39581 & 1.10979 & 105 & -0.19617 & 0.99439 & 0.0388 & 1.00173 & 74 \\
\hline-1.34879 & 0.92891 & 7.57328 & 1.36512 & 106 & -0.21968 & 0.99423 & 0.27641 & 1.01238 & 75 \\
\hline-1.671 & 0.91204 & 11.26464 & 1.56082 & 107 & -0.22264 & 0.99388 & 0.05505 & 1.00246 & 76 \\
\hline-1.62326 & 0.90559 & 12.86616 & 1.64893 & 108 & -0.28585 & 0.98977 & -0.36288 & 0.98386 & 77 \\
\hline-1.41188 & 0.89339 & 21.54959 & 2.15622 & 109 & -0.03461 & 0.99898 & -0.23634 & 0.98947 & 78 \\
\hline-0.19883 & 0.96434 & 5.32931 & 1.25156 & 110 & -0.02895 & 0.99894 & -0.40162 & 0.98215 & 79 \\
\hline 0.45661 & 1.01388 & -1.63405 & 0.92838 & 111 & -0.1448 & 0.99419 & 0.09907 & 1.00443 & 80 \\
\hline 0.43648 & 1.02019 & -3.1018 & 0.8664 & 112 & 0.05912 & 1.00176 & -0.66888 & 0.97036 & 81 \\
\hline 0.39885 & 1.02065 & -3.64277 & 0.84412 & 113 & -0.06506 & 0.99629 & -0.30412 & 0.98647 & 82 \\
\hline 0.51545 & 1.02234 & -3.09798 & 0.86655 & 114 & -0.09916 & 0.99402 & -0.31999 & 0.98576 & 83 \\
\hline 0.18666 & 1.00603 & -2.56476 & 0.88881 & 115 & 0.12222 & 1.00376 & -0.33814 & 0.98496 & 84 \\
\hline 0.08743 & 1.0025 & -2.28036 & 0.90081 & 116 & -0.02976 & 0.99777 & -0.25383 & 0.9887 & 85 \\
\hline-0.95864 & 0.96685 & 0.85049 & 1.03834 & 117 & -0.1687 & 0.99488 & -0.24352 & 0.98916 & 86 \\
\hline-1.49929 & 0.93114 & 7.17084 & 1.34444 & 118 & -0.41509 & 0.98649 & 0.64411 & 1.02897 & 87 \\
\hline-1.87739 & 0.8952 & 13.80642 & 1.70152 & 119 & -0.44093 & 0.98666 & 0.99128 & 1.04475 & 88 \\
\hline-2.20923 & 0.85347 & 43.40559 & 3.59653 & 120 & 0.14795 & 1.00286 & -0.08664 & 0.99614 & 89 \\
\hline-0.94389 & 0.93922 & 13.46719 & 1.68247 & 121 & -0.38344 & 0.98849 & 0.28286 & 1.01267 & 90 \\
\hline-0.6344 & 0.95165 & 10.68852 & 1.52958 & 122 & -0.40062 & 0.9876 & 0.21844 & 1.00978 & 91 \\
\hline-1.56573 & 0.90021 & 26.30679 & 2.45237 & 123 & -0.40772 & 0.98641 & 0.38977 & 1.01748 & 92 \\
\hline-0.24454 & 0.99086 & 0.90004 & 1.04059 & 124 & -0.47661 & 0.97976 & 0.93146 & 1.04202 & 93 \\
\hline
\end{tabular}

ويلاحظ من الجدول أن قيم إحصائية حسن المطابقة الخارجية قد تراوحت بين (1.648- 0.478) وبمتوسط

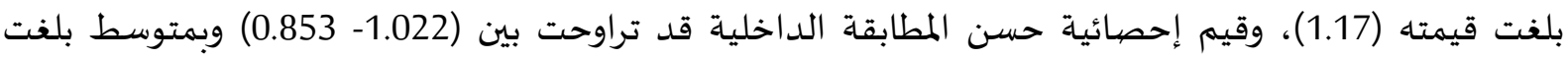

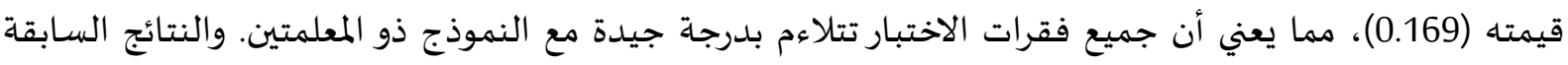
تؤكد ملاءمة بيانات الاختبار للنموذج المستخدم. وفي هذا إجابة عن السؤال الثالث من تساؤلات الدراسة. 
نتائج السؤال الرابع: ما تقدير معالم الفقرات في ضوء النموذج اللوغارتيمي المناسب؟

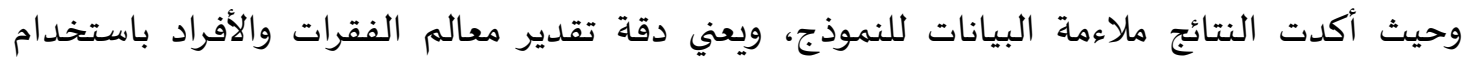
النموذج ذو المعلمتين، لذا تم تقدير معالم فقرات الاختبار وفقاً للنموذج ثنائي المعلمتين وهما معلمتي الصعوبة دوفية

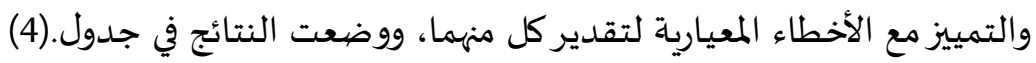

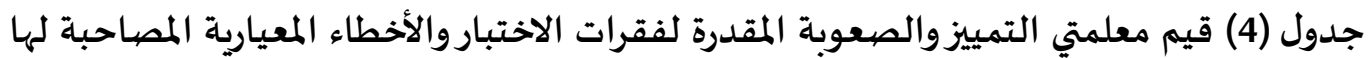

\begin{tabular}{|c|c|c|c|c|c|c|c|c|c|}
\hline $\begin{array}{c}\text { الخطاري } \\
\text { SE }\end{array}$ & 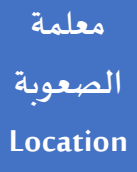 & $\begin{array}{c}\text { المعيارئ } \\
\text { SE }\end{array}$ & $\begin{array}{l}\text { معلمة } \\
\text { Slope }\end{array}$ & 高 & $\begin{array}{c}\text { الخعياري } \\
\text { SE }\end{array}$ & 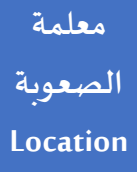 & $\begin{array}{l}\text { الخطيارئ } \\
\text { SE }\end{array}$ & التمييز & 高 \\
\hline 0.08 & -1.50 & 0.09 & 2.53 & 63 & 0.28 & -2.65 & 0.13 & 1.05 & 1 \\
\hline 0.06 & -1.50 & 0.07 & 1.94 & 64 & 0.12 & -1.70 & 0.11 & 1.22 & 2 \\
\hline 0.09 & - 0.97 & 0.10 & 1.13 & 65 & 0.09 & -1.69 & 0.15 & 1.79 & 3 \\
\hline 0.06 & -0.73 & 0.06 & 1.32 & 66 & 0.11 & - 1.77 & 0.13 & 1.47 & 4 \\
\hline 0.17 & -0.44 & 0.07 & 0.78 & 67 & 0.08 & -1.06 & 0.09 & 1.16 & 5 \\
\hline 3.93 & -0.89 & 0.08 & 1.41 & 68 & 0.11 & -0.72 & 0.07 & 0.72 & 6 \\
\hline 0.08 & 0.94 & 0.08 & 0.49 & 69 & 0.08 & -0.69 & 0.08 & 0.90 & 7 \\
\hline 0.27 & 7.70 & 0.08 & 0.14 & 70 & 0.08 & 0.14 & 0.07 & 0.85 & 8 \\
\hline 0.26 & 0.42 & 0.08 & 0.92 & 71 & 0.09 & 0.39 & 0.07 & 0.73 & 9 \\
\hline 0.17 & 2.15 & 0.07 & 0.61 & 72 & 0.16 & 0.88 & 0.07 & 0.53 & 10 \\
\hline 0.17 & 2.14 & 0.08 & 0.65 & 73 & 2.00 & 5.55 & 0.07 & 0.20 & 11 \\
\hline 0.12 & 1.60 & 0.08 & 0.73 & 74 & 0.10 & - 1.85 & 0.18 & 1.86 & 12 \\
\hline 0.06 & 1.44 & 0.08 & 0.68 & 75 & 0.06 & -1.57 & 0.22 & 2.61 & 13 \\
\hline 0.07 & 1.20 & 0.08 & 0.85 & 76 & 0.07 & -1.58 & 0.18 & 2.15 & 14 \\
\hline 0.06 & -0.28 & 0.10 & 1.07 & 77 & 0.07 & -1.48 & 0.15 & 1.95 & 15 \\
\hline 0.05 & -0.37 & 0.07 & 0.93 & 78 & 0.08 & -1.31 & 0.11 & 1.38 & 16 \\
\hline 0.07 & -0.16 & 0.08 & 1.04 & 79 & 0.06 & -1.04 & 0.11 & 1.50 & 17 \\
\hline 0.07 & -0.53 & 0.08 & 1.42 & 80 & 0.10 & -0.97 & 0.08 & 0.93 & 18 \\
\hline 0.18 & 0.17 & 0.08 & 0.88 & 81 & 0.07 & -0.73 & 0.08 & 1.07 & 19 \\
\hline 0.14 & 0.43 & 0.08 & 0.99 & 82 & 0.09 & 0.26 & 0.07 & 0.73 & 20 \\
\hline 0.30 & 1.62 & 0.09 & 0.72 & 83 & 0.77 & 2.81 & 0.06 & 0.25 & 21 \\
\hline 0.24 & 1.44 & 0.077 & 0.83 & 84 & 0.10 & 0.66 & 0.07 & 0.78 & 22 \\
\hline 0.19 & 2.37 & 0.08 & 0.62 & 85 & 1.14 & 3.92 & 0.07 & 0.24 & 23 \\
\hline 0.52 & 2.26 & 0.08 & 0.75 & 86 & 0.05 & -1.49 & 0.25 & 3.00 & 24 \\
\hline 0.06 & 1.60 & 0.09 & 0.65 & 87 & 0.04 & -1.28 & 0.21 & 2.86 & 25 \\
\hline 0.05 & 3.13 & 0.09 & 0.48 & 88 & 0.05 & -1.44 & 0.21 & 2.65 & 26 \\
\hline 0.06 & -0.27 & 0.07 & 1.17 & 89 & 0.05 & -1.49 & 0.23 & 2.78 & 27 \\
\hline 0.15 & -0.32 & 0.08 & 1.37 & 90 & 0.06 & -1.08 & 0.13 & 1.85 & 28 \\
\hline 0.06 & -0.37 & 0.0889 & 1.19 & 91 & 0.09 & -1.04 & 0.09 & 1.05 & 29 \\
\hline 0.06 & 0.79 & 0.09 & 0.54 & 92 & 0.05 & -0.79 & 0.12 & 1.78 & 30 \\
\hline 0.07 & 0.19 & 0.09 & 1.18 & 93 & 0.10 & -0.24 & 0.07 & 0.64 & 31 \\
\hline
\end{tabular}




\begin{tabular}{|c|c|c|c|c|c|c|c|c|c|}
\hline $\begin{array}{c}\text { المخطائ } \\
\text { SE }\end{array}$ & 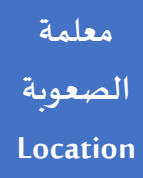 & المخطأ المياري & $\begin{array}{l}\text { معلمة } \\
\text { Slope }\end{array}$ & $\frac{\overline{7}}{9}$ & $\begin{array}{l}\text { الخطيارئ } \\
\text { SE }\end{array}$ & 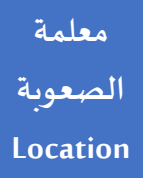 & $\begin{array}{c}\text { المخطائل } \\
\text { المياري } \\
\text { SE }\end{array}$ & $\begin{array}{l}\text { معلمة } \\
\text { Slope }\end{array}$ & 高 \\
\hline 0.08 & 0.37 & 0.08 & 1.16 & 94 & 0.14 & -1.32 & 0.08 & 0.76 & 32 \\
\hline 0.18 & 0.58 & 0.09 & 1.16 & 95 & 0.09 & -0.10 & 0.07 & 0.74 & 33 \\
\hline 0.18 & 1.03 & 0.09 & 1.26 & 96 & 0.18 & 0.96 & 0.06 & 0.49 & 34 \\
\hline 0.23 & 1.83 & 0.08 & 0.81 & 97 & 0.37 & 1.85 & 0.06 & 0.36 & 35 \\
\hline 0.38 & 1.98 & 0.10 & 0.89 & 98 & 0.04 & -1.29 & 0.29 & 3.70 & 36 \\
\hline 0.31 & 2.30 & 0.28 & 0.83 & 99 & 0.04 & -1.21 & 0.26 & 3.50 & 37 \\
\hline 0.33 & 2.78 & 0.15 & 0.59 & 100 & 0.04 & -1.37 & 0.25 & 3.12 & 38 \\
\hline 0.26 & -2.64 & 0.10 & 0.80 & 101 & 0.04 & -1.36 & 0.28 & 3.45 & 39 \\
\hline 0.30 & -2.90 & 0.11 & 1.60 & 102 & 0.04 & -1.42 & 0.28 & 3.35 & 40 \\
\hline 0.14 & -2.62 & 0.11 & 1.16 & 103 & 0.04 & -1.46 & 0.27 & 3.23 & 41 \\
\hline 0.09 & -2.60 & 0.09 & 0.80 & 104 & 0.04 & -1.40 & 0.36 & 4.16 & 42 \\
\hline 0.065 & -1.83 & 0.10 & 1.13 & 105 & 0.04 & -1.38 & 0.29 & 3.54 & 43 \\
\hline 0.055 & -1.39 & 0.14 & 1.31 & 106 & 0.03 & -1.36 & 0.36 & 4.21 & 44 \\
\hline 0.048 & -0.63 & 0.13 & 1.26 & 107 & 0.04 & -1.43 & 0.31 & 3.64 & 45 \\
\hline 0.05 & 0.45 & 0.14 & 1.47 & 108 & 0.03 & -1.29 & 0.37 & 4.45 & 46 \\
\hline 0.06 & 0.82 & 0.16 & 2.17 & 109 & 0.04 & -1.42 & 0.35 & 4.01 & 47 \\
\hline 0.092 & 0.99 & 0.20 & 1.93 & 110 & 0.05 & -1.43 & 0.22 & 2.76 & 48 \\
\hline 0.33 & 1.17 & 0.08 & 1.99 & 111 & 0.04 & -1.47 & 0.30 & 3.44 & 49 \\
\hline 0.10 & 1.75 & 0.10 & 1.90 & 112 & 0.05 & -1.40 & 0.19 & 2.44 & 50 \\
\hline 0.13 & 3.12 & 0.10 & 1.33 & 113 & 0.04 & -1.39 & 0.34 & 3.99 & 51 \\
\hline 0.16 & -1.01 & 0.09 & 0.88 & 114 & 0.05 & -1.38 & 0.23 & 2.97 & 52 \\
\hline 0.13 & -1.65 & 0.10 & 1.03 & 115 & 0.04 & -1.28 & 0.27 & 3.51 & 53 \\
\hline 0.05 & -1.86 & 0.10 & 1.03 & 116 & 0.03 & -1.30 & 0.34 & 4.09 & 54 \\
\hline 0.05 & -1.58 & 0.10 & 0.98 & 117 & 0.04 & -1.24 & 0.25 & 3.29 & 55 \\
\hline 0.04 & -0.57 & 0.13 & 1.38 & 118 & 0.15 & -1.70 & 0.09 & 0.97 & 56 \\
\hline 0.04 & -0.36 & 0.16 & 1.40 & 119 & 0.10 & -0.89 & 0.08 & 0.81 & 57 \\
\hline 0.04 & 0.18 & 0.18 & 1.55 & 120 & 10.18 & 10.16 & 9.81 & 0.14 & 58 \\
\hline 0.05 & 0.64 & 0.09 & 1.96 & 121 & 0.06 & -1.42 & 0.16 & 2.03 & 59 \\
\hline 0.08 & 0.88 & 0.07 & 2.35 & 122 & 0.06 & -2.65 & 0.21 & 1.05 & 60 \\
\hline 0.06 & 1.22 & 0.10 & 2.50 & 123 & 0.07 & -1.70 & 0.15 & 1.21 & 61 \\
\hline 0.09 & -1.50 & 0.06 & 2.53 & 124 & 0.08 & -1.69 & 0.09 & 1.78 & 62 \\
\hline 0.25 & -0.09 & 0.22 & 1.59 & \multicolumn{6}{|c|}{ المتوسط الحسابي الكلي } \\
\hline
\end{tabular}

يلاحظ من الجدول أن قيم معلمة التمييز تراوحت بين (4.451) للفقرة 46 وهي القيمة الأكبر و(0.143)

للفقرة 67 وهي القيمة الأصغر، وبمتوسط بلغت قيمته (1.592) والشكل (2) و (3) يوضح المنحنى المميز للفقرتين 46

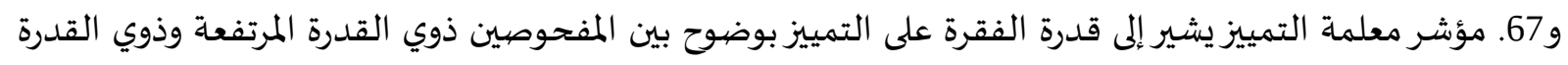




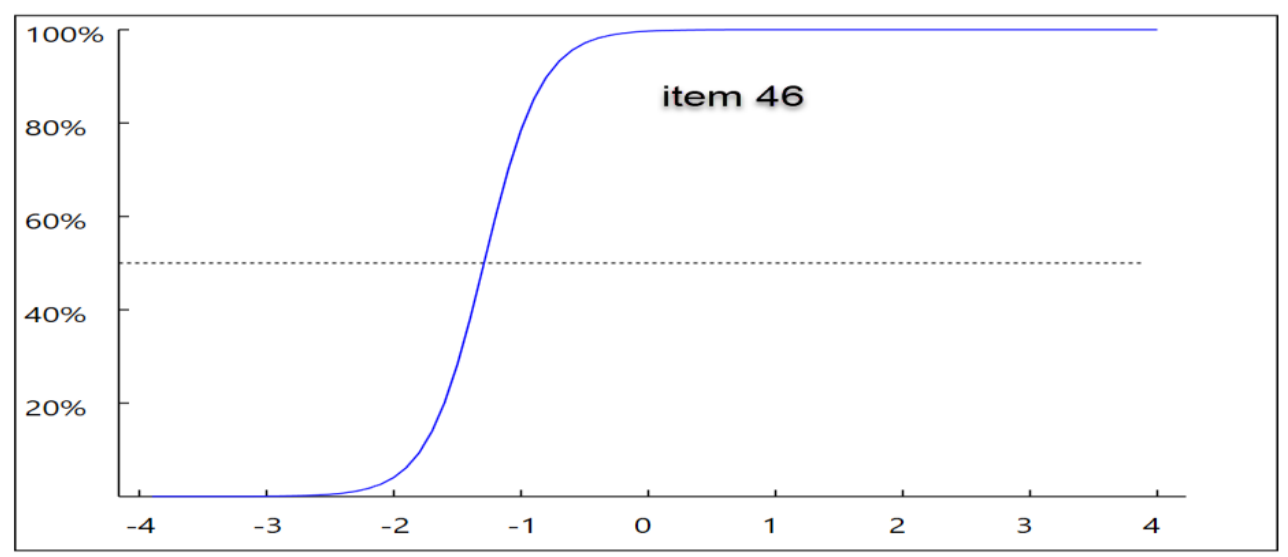

شكل (2) المنحنى المميز للفقرة 46

ويلاحظ من خلال شكل (2) أن الفقرة 46 تميزت بشكل كبير بين المختبرين ذوي القدرة المرتفعة وذوي المبري

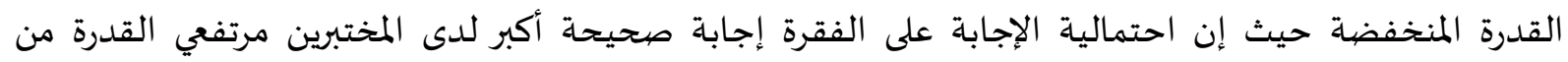

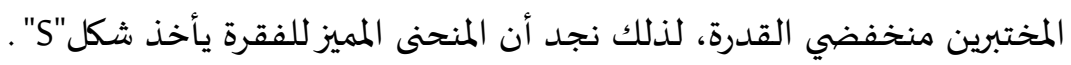

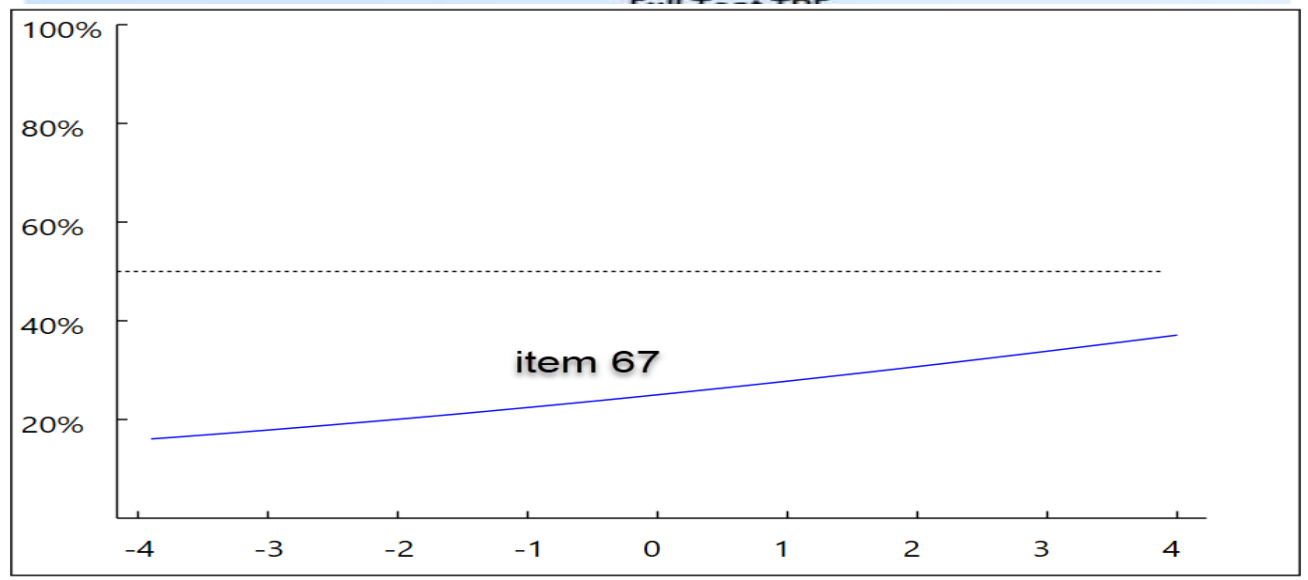

شكل (3) المنحنى المميز للفقرة 67

في شكل (3) يتضح أن الفقرة 67 والحاصلة على أقل قيمة للتمييز يلاحظ أن قدرتها على التمييز بين المختبرين مرتفعي ومنخفضي القدرة أقل بكثير، حيث لا يوجد اختلاف كبير بين احتمالية الإجابة عليها إجابة صحيحة بين المختبرين مرتفعي ومنخفضي القدرة. لذلك فإن المنحنى يأخذ خط شبة مستقيم، ولكناه مائل، حيث إن

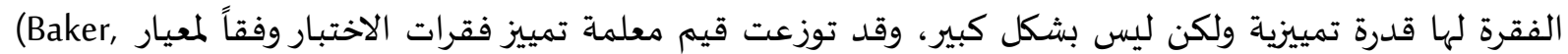

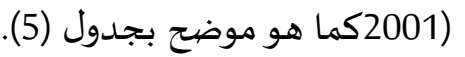

جدول (5) توزيع قيم معلمة تمييز فقرات الاختبار وفقاً لمعايير بيكر

\begin{tabular}{|c|c|c|c|c|c|c|}
\hline مرتفع جداً & مرتفع & متوسط & منخفض & منخفض جداً & غير مميز & مسـتوى التميلز \\
\hline $1.70<$ & $1.35-1.69$ & $1.34-0.65$ & $0.64-0.35$ & $0.34-0.01$ & صفر & قيم معلمة التمييز \\
\hline 41 & 16 & 53 & 9 & 5 & - & عدد الفقرات \\
\hline
\end{tabular}

يتضح من الجدول (5) أن هنالك (53) فقرة تمييزها متوسط، إذ تراوحت بين (0.65- 1.34)، كما أن هنالك (16) فقرة تمييزها مرتفع حيث تراوح بين (1.35- 1.69)، بينما هنالك (41) فقرة تمييزها مرتفع جداً حيث كيث كانت أكبر الكبر من (1.70) وذلك لأن الاختبار مكون من أربعة اختبارات فرعية حيث اختبار التناظر والفئات مكون ثلاث سلاسل كل 
سلسلة مكونة من 12 فقرة، وكذلك اختبار الفسيفساء والانماط مكون سلسلتين كل سلسلة مكونة من 13 فقرة

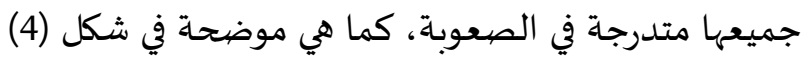

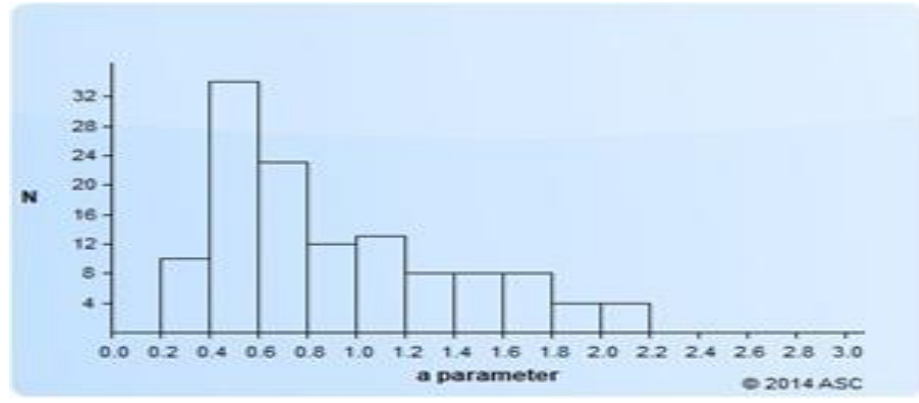

شكل (4) توزيع قيم معلمة تمييز فقرات الاختبار

والنتائج السابقة تؤكد أن فقرات اختبار سنجدرس أومن تتمتع بقدرة تمييزية جيدة وهو ما يؤكده المنحنى تميز فقرات الاتبار

المميز للاختبار ككل والذي يمثل محصلة خصائص الفقرات والمعروض في شكل(5) . Full Test TRF

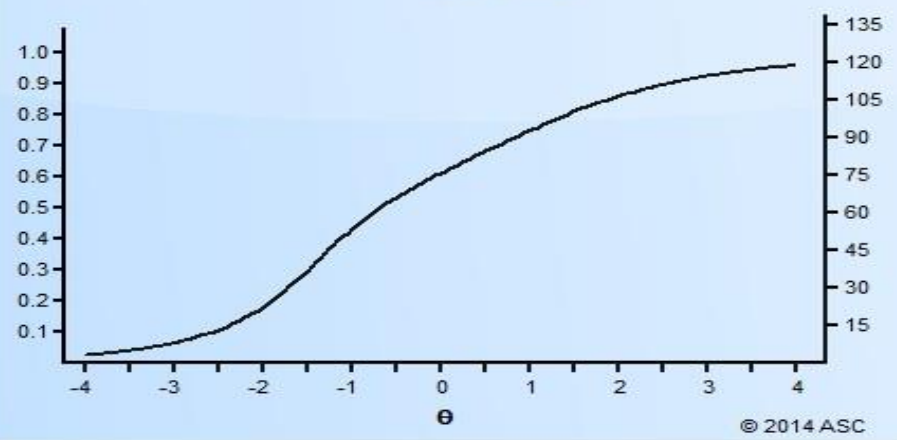

شكل (5) المنحنى المميز لاختبار سنجدرس أومن في ضوء النموذج اللوغاريتمي ثنائي المعالم

أيضاً يلاحظ من جدول (4) أن الأخطاء المعيارية لقيم معلمة التمييز قد تراوحت بين (0.369- 0.068) وبمتوسط (0.223)، وهي قيم صغيرة تدل على دقة تقدير قيم معالم التمييز.

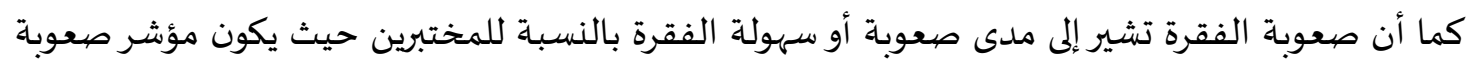
الفقرة السهلة صغير وسالب، بينما يكون للفقرة الصعبة كبير وموجب، وبالنظر إلى قيم معالم صعوبة الفية الفقرات

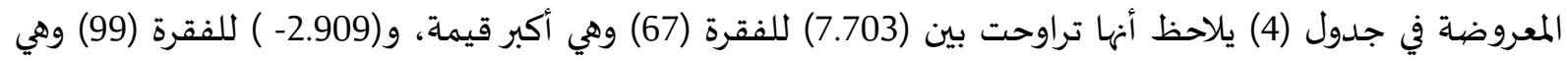
أصغر قيمة، وبمتوسط بلغت قيمته (0.168- ) وانحراف معياري (1.704). والشكل (5) و (6) يوضح المترو المنحنى المميز للفقرتين (67) و (99). 


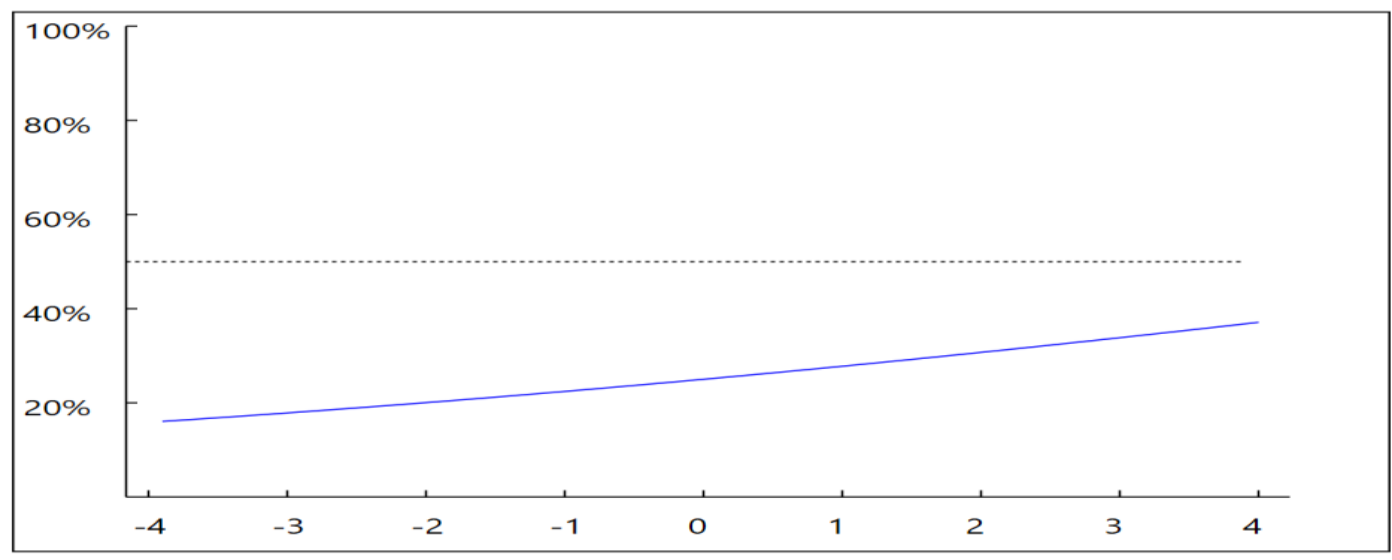

شكل(6) المنحنى المميز للفقرة سبعة وستون

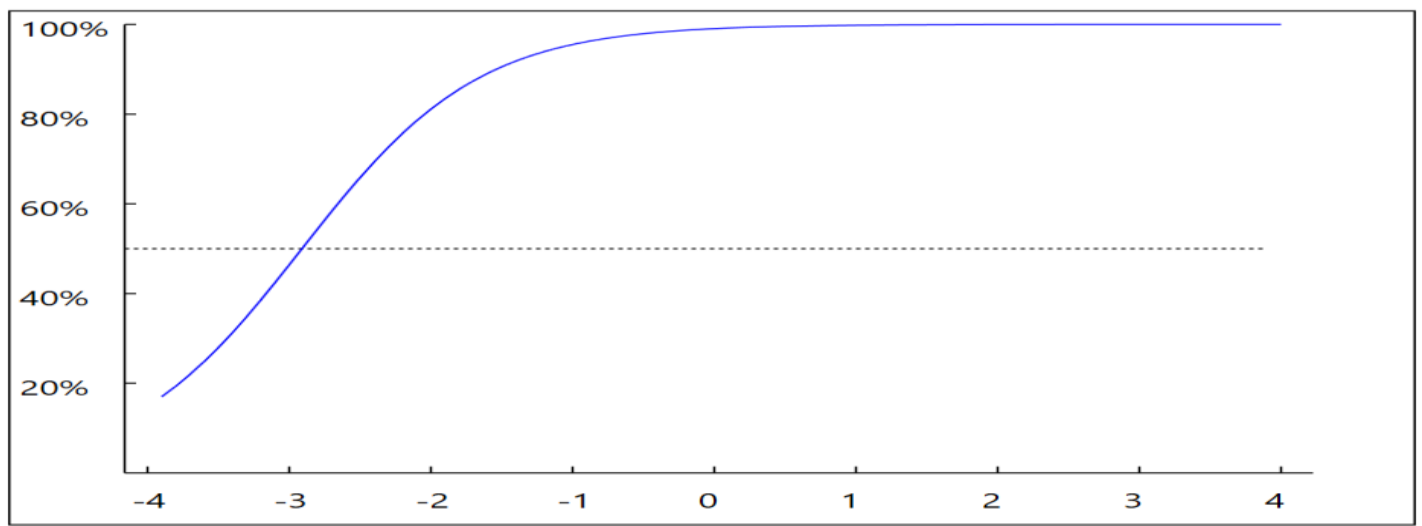

شكل (7) المنحنى المميز للفقرة تسعة وتسعون

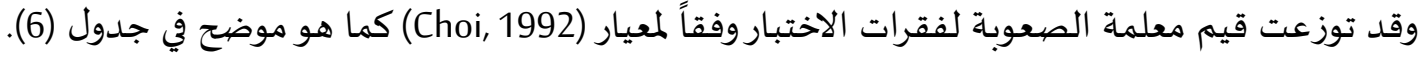

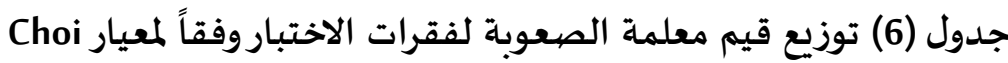

\begin{tabular}{|c|c|c|c|}
\hline صعبة & متوسطة الصعوبة & سهلة & مستوى الصعوبة \\
\hline أكبر من 0.50 & من- 0.50 إلى +0.50 & أقل من- 0.50 & مدى قيم معلمة الصعوبة \\
\hline 36 & 23 & 65 & عدد الفقرات \\
\hline
\end{tabular}

ويلاحظ من جدول (6) أن (65) فقرة كانت سهلة حيث قلت قيم معلمة الصعوبة لها عن (- 0.50)، كما أن

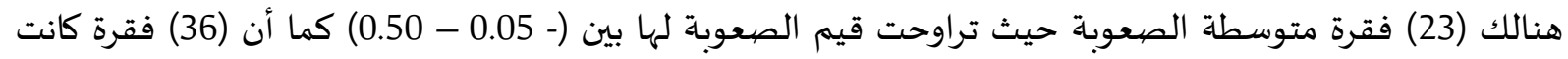
صعبة حيث كانت قيم معلمة الصعوبة لها أكبر من (0.50).

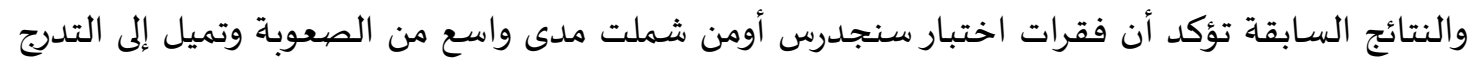

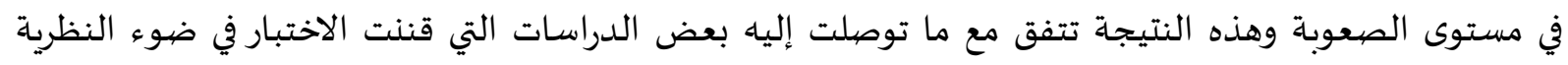

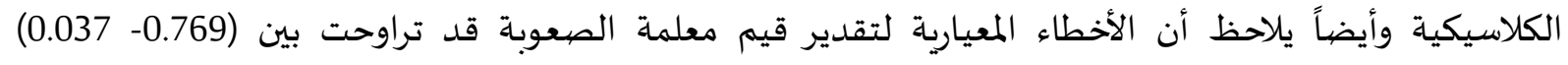
وبمتوسط (0.151) وانحراف معياري (1.949) هي قيم صغيرة تدل على أن قيم معالم الصعوبة تم تقديرها بدرجة قريبة من الدقة. 
نتائج السؤال الخامس: ما تقدير دالة المعلومات لفقرات الاختبار؟

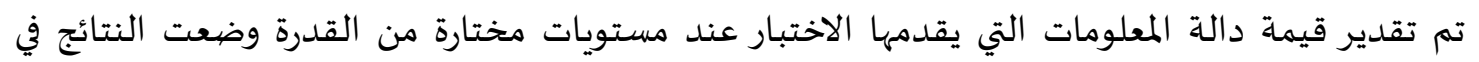
جدول (7) كما عرضت في شكل(8) . جدول (7) تقديرات قيم دالة معلومات الاختبار عند مستويات مختارة من القدرة

\begin{tabular}{|c|c|c|c|}
\hline دالة المعلومات & مستوى القدرة & دالة المعلومات & مستوى القـدرة \\
\hline 6.94465 & صفر & 0.7583 & $4-$ \\
\hline 6.27278 & 0.25 & 0.85876 & $3.75-$ \\
\hline 5.68974 & 0.50 & 0.97457 & $3.5-$ \\
\hline 5.1809 & 0.75 & 1.10845 & $3.25-$ \\
\hline 4.73429 & 1 & 1.26373 & $3-$ \\
\hline 4.34005 & 1.25 & 1.44444 & $2.75-$ \\
\hline 3.99004 & 1.50 & 1.65553 & $2.5-$ \\
\hline 3.67756 & 1.75 & 1.90313 & $2.25-$ \\
\hline 3.39704 & 2 & 2.1948 & $2-$ \\
\hline 3.14389 & 2.25 & 2.53993 & $1.75-$ \\
\hline 2.91432 & 2.50 & 2.95018 & $1.5-$ \\
\hline 2.70518 & 2.75 & 3.44 & $1.25-$ \\
\hline 2.5139 & 3 & 4.02717 & $1-$ \\
\hline 2.3383 & 3.25 & 4.73336 & $0.75-$ \\
\hline 2.17662 & 3.50 & 5.58453 & $0.5-$ \\
\hline 2.02736 & 3.75 & 6.61095 & $0.25-$ \\
\hline 1.88927 & 4 & 7.84638 & $0.10-$ \\
\hline
\end{tabular}

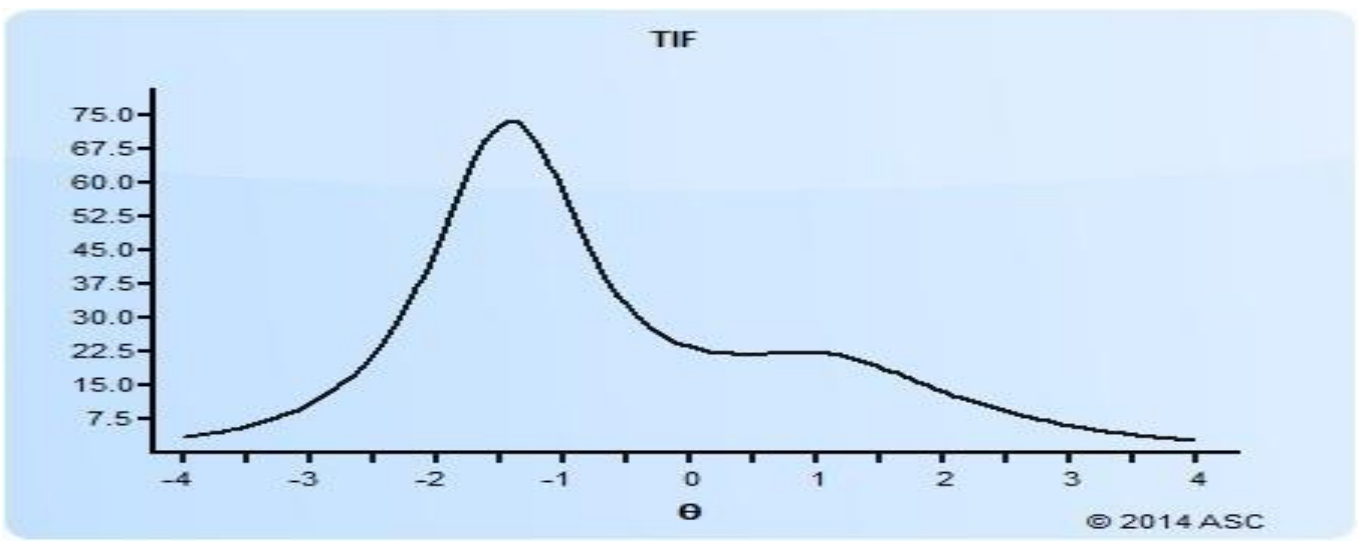

$$
\text { شكل (8) دالة معلومات الاختبار }
$$

ويلاحظ من جدول (7) وشكل (8) السابقين أن أول قيمة لدالة المعلومات قدمها الاختبار وفقاً للنموذج الاتبار

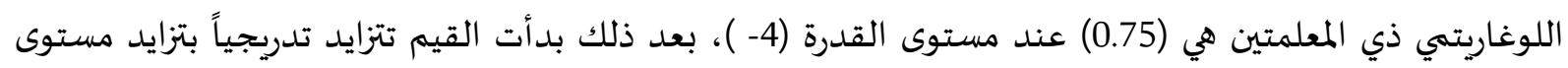


القدرة، إلى أن وصلت إلى أكبر قيمة (7.85) والمناظرة لمستوى القدرة (0.10- )، ثم بدأت بالتناقص التدريجي بتناقص ألتص

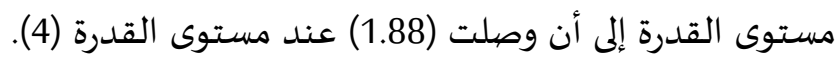

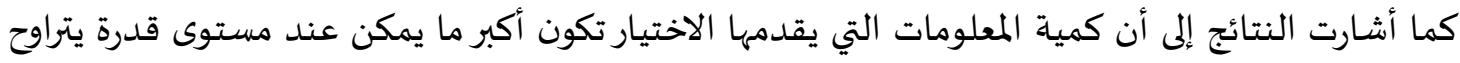

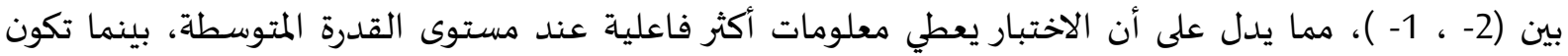

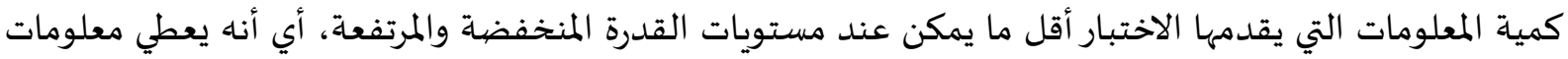

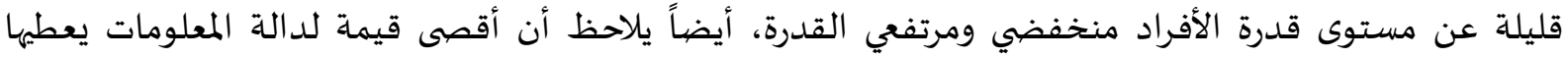

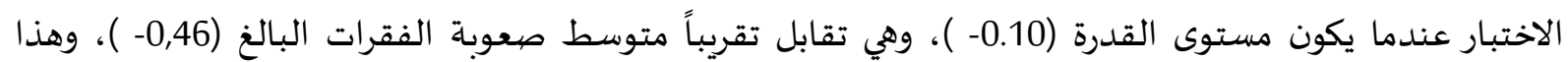
يتطابق مع النموذج اللوغاريتهي ذو المعلمتين، حيث إن دالة المعلومات تكون أقصى ما يمكن عندما عندا تكون قيمة $(\theta=b)$.

النتائج السابقة تؤكد تمتع اختبار سنجدرس أومن بخصائص سيكومترية جيدة في ضوء النموذج

اللوغاريتهي ذو المعلمتين، تسهم في قياس القدرات العقلية للمختبرين بدرجة عالية،

نتائج السؤال السـادس: ما تقدير معلمة القدرة للأفراد في ضوء النموذج اللوغاريتمي المناسب؟

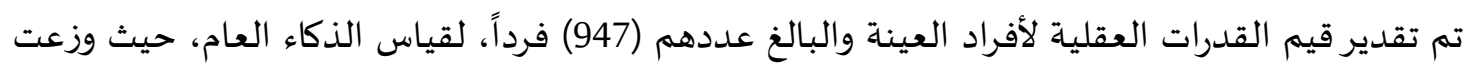

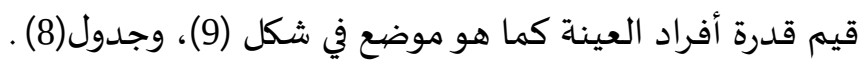

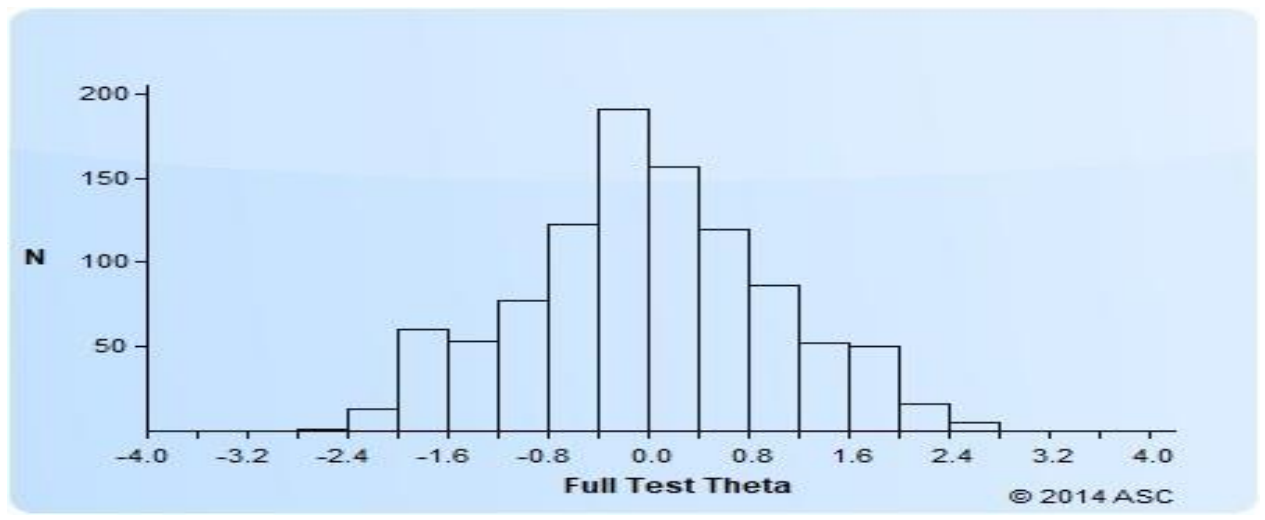

شكل (9) توزيع قيم قدرة الأفراد على مستويات القدرة المختلفة

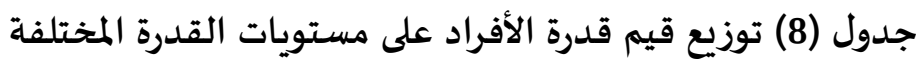

\begin{tabular}{|c|c|c|c|}
\hline | & التكرارات & التكرارات & Below- 4 \\
\hline 157 & 0.0 to 0.4 & 0 & -4.0 to- 3.6 \\
\hline 120 & 0.4 to 0.8 & 0 & -3.6 to- 3.2 \\
\hline 86 & 0.8 to 1.2 & 0 & -3.2 to- 2.8 \\
\hline 52 & 1.2 to 1.6 & 0 & -2.8 to- 2.4 \\
\hline 50 & 1.6 to 2.0 & 1 & -2.4 to- 2.0 \\
\hline 5 & 2.0 to 2.4 & 13 & -2.0 to- 1.6 \\
\hline 0 & 2.4 to 2.8 & 60 & -1.6 to- 1.2 \\
\hline
\end{tabular}


المجلة العربية للطوم ونثر الأبحاث ـ مجلة العلوم التربوية والنفسية ـ المجلد الساس ـ العلد العاثر ـ فبراير 2022م

\begin{tabular}{|c|c|c|c|}
\hline التكرارات & المدىى & التكرارات & المدى \\
\hline 0 & 3.2 to 3.6 & 77 & -1.2 to- 0.8 \\
\hline 0 & 3.6 to 4.0 & 123 & -0.8 to- 0.4 \\
\hline 0 & Above +4 & 191 & -0.4 to 0.0 \\
\hline
\end{tabular}

من خلال الجدول السابق يتضح أن قيم قدرة الأفراد تراوحت بين (2.41- ، 3.20) وبمتوسط (0,0047).

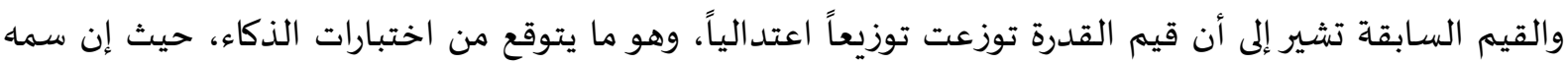

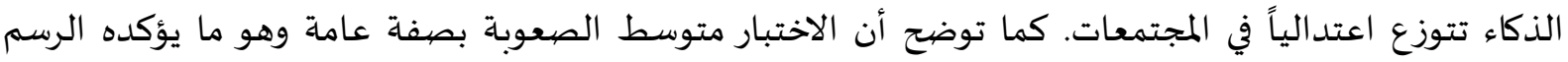

البياني للتوزيع المشترك لمعلمتي الصعوبة والقدرة كما في شكل (10).

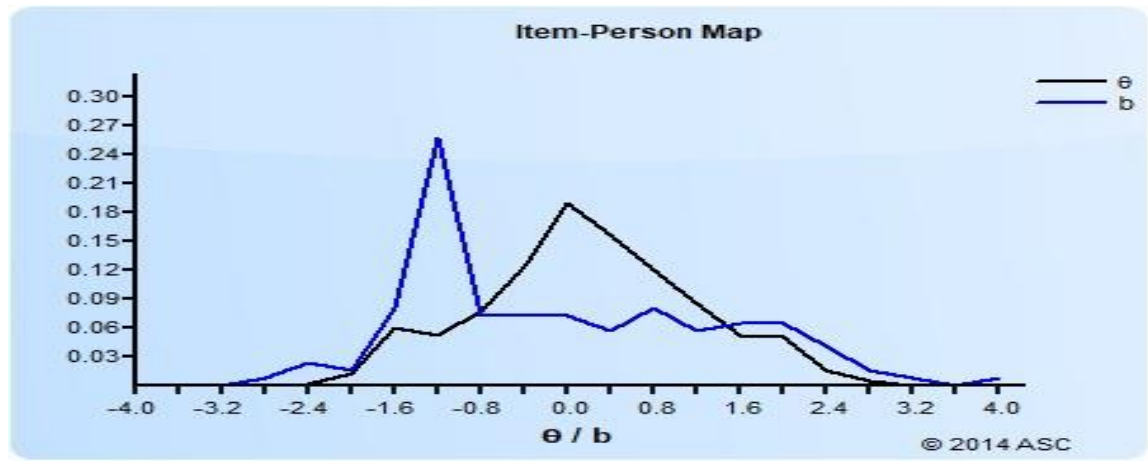

شكل (10) التوزيع المشترك لمعلمتي صعوبة الفقرات وقدرة الأفراد

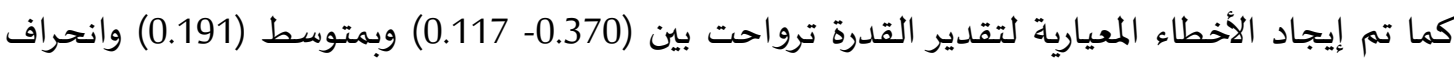

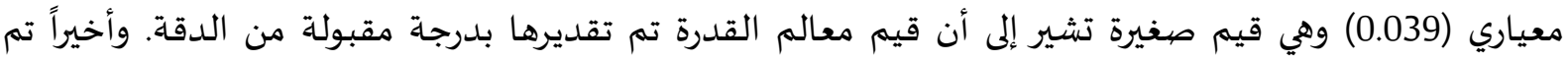

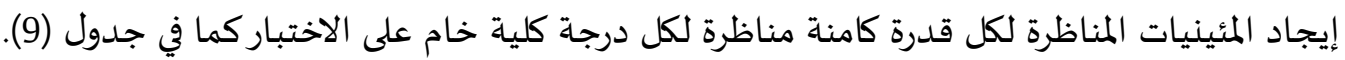
جدول (9) المئينيات المناظرة لكل قدرة مناظرة لكل درجة كلية خام

\begin{tabular}{|c|c|c|c|c|c|c|c|c|}
\hline المئينيات & $\begin{array}{c}\text { القدرة } \\
(\theta)\end{array}$ & الدرجة الكلية & المئينيات & $\begin{array}{c}\text { القدرة } \\
(\theta)\end{array}$ & الدرجة الكلية & المئينيات & $\begin{array}{c}\text { القدرة } \\
(\theta)\end{array}$ & الدرجة الكلية \\
\hline 69 & 0.46 & 85 & 34 & -1.34 & 43 & 1 & -2.88 & 1 \\
\hline 69 & 0.56 & 86 & 36 & -1.32 & 44 & 2 & -2.56 & 2 \\
\hline 70 & 0.62 & 87 & 36 & -1.32 & 45 & 2 & -2.5 & 3 \\
\hline 71 & 0.64 & 88 & 37 & -1.28 & 46 & 3 & -2.48 & 4 \\
\hline 72 & 0.66 & 89 & 38 & -1.26 & 47 & 4 & -2.34 & 5 \\
\hline 73 & 0.74 & 90 & 39 & -1.22 & 48 & 5 & -2.32 & 6 \\
\hline 73 & 0.76 & 91 & 40 & -1.08 & 49 & 6 & -1.92 & 7 \\
\hline 74 & 0.8 & 92 & 41 & -1.06 & 50 & 7 & -1.8 & 8 \\
\hline 75 & 0.82 & 93 & 41 & -1.06 & 51 & 7 & -1.8 & 9 \\
\hline 76 & 0.88 & 94 & 42 & -1 & 52 & 8 & -1.78 & 10 \\
\hline 77 & 0.98 & 95 & 43 & -0.98 & 53 & 9 & -1.74 & 11 \\
\hline 77 & 1 & 96 & 44 & -0.94 & 54 & 10 & -1.7 & 12 \\
\hline 78 & 1.12 & 97 & 44 & -0.92 & 55 & 10 & -1.66 & 13 \\
\hline 79 & 1.14 & 98 & 45 & -0.9 & 56 & 12 & -1.64 & 14 \\
\hline 80 & 1.2 & 99 & 46 & -0.84 & 57 & 12 & -1.64 & 15 \\
\hline
\end{tabular}


المجلة العربية للعلوم ونشر الأبحاث ـ مجلة العلوم التربوية والنفسية ـ المجلد الساس ـ العلد العاثر ـ فبراير 2022م

\begin{tabular}{|c|c|c|c|c|c|c|c|c|}
\hline المئينيات & $\begin{array}{c}\text { القدرة } \\
(\theta)\end{array}$ & الدرجة الكلية & المئينيات & $\begin{array}{c}\text { القدرة } \\
(\theta)\end{array}$ & الدرجة الكلية & المئينيات & $\begin{array}{c}\text { القدرة } \\
(\theta)\end{array}$ & الدرجة الكلية \\
\hline 81 & 1.28 & 100 & 47 & -0.8 & 58 & 13 & -1.6 & 16 \\
\hline 82 & 1.3 & 101 & 48 & -0.72 & 59 & 15 & -1.56 & 17 \\
\hline 82 & 1.3 & 102 & 48 & -0.72 & 60 & 15 & -1.56 & 18 \\
\hline 83 & 1.32 & 103 & 50 & -0.68 & 61 & 15 & -1.56 & 19 \\
\hline 84 & 1.4 & 104 & 50 & -0.66 & 62 & 17 & -1.54 & 20 \\
\hline 84 & 1.42 & 105 & 51 & -0.64 & 63 & 17 & -1.54 & 21 \\
\hline 84 & 1.44 & 106 & 52 & -0.58 & 64 & 17 & -1.54 & 22 \\
\hline 86 & 1.58 & 107 & 52 & -0.52 & 65 & 17 & -1.54 & 23 \\
\hline 87 & 1.66 & 108 & 53 & -0.42 & 66 & 19 & -1.52 & 24 \\
\hline 88 & 1.7 & 109 & 55 & -0.36 & 67 & 21 & -1.5 & 25 \\
\hline 89 & 1.78 & 110 & 55 & -0.36 & 68 & 21 & -1.5 & 26 \\
\hline 89 & 1.78 & 111 & 55 & -0.36 & 69 & 23 & -1.48 & 27 \\
\hline 90 & 1.8 & 112 & 56 & -0.32 & 70 & 23 & -1.48 & 28 \\
\hline 91 & 1.82 & 113 & 58 & -0.26 & 71 & 23 & -1.48 & 29 \\
\hline 92 & 1.96 & 114 & 58 & -0.26 & 72 & 25 & -1.46 & 30 \\
\hline 93 & 1.98 & 115 & 59 & -0.22 & 73 & 25 & -1.46 & 31 \\
\hline 94 & 2.04 & 116 & 60 & -0.16 & 74 & 25 & -1.46 & 32 \\
\hline 94 & 2.04 & 117 & 60 & -0.08 & 75 & 25 & -1.46 & 33 \\
\hline 95 & 2.2 & 118 & 61 & 0.14 & 76 & 27 & -1.44 & 34 \\
\hline 96 & 2.22 & 119 & 62 & 0.16 & 77 & 29 & -1.42 & 35 \\
\hline 97 & 2.3 & 120 & 63 & 0.18 & 78 & 29 & -1.42 & 36 \\
\hline 98 & 2.46 & 121 & 63 & 0.2 & 79 & 29 & -1.42 & 37 \\
\hline 98 & 2.5 & 122 & 65 & 0.24 & 80 & 29 & -1.42 & 38 \\
\hline 99 & 2.88 & 123 & 66 & 0.36 & 81 & 31 & -1.4 & 39 \\
\hline \multirow[t]{3}{*}{100} & 4 & 124 & 66 & 0.36 & 82 & 32 & -1.36 & 40 \\
\hline & & & 67 & 0.4 & 83 & 34 & -1.34 & 41 \\
\hline & & & 68 & 0.42 & 84 & 34 & -1.34 & 42 \\
\hline
\end{tabular}

كما تم تصنيف المستويات العقلية للمفحوصين في ضوء المعايير المئينية المعروضة في جدول (9)، وذلك

بالرجوع للمستويات العقلية التي حددها كلا من (Tellegen \& Laros,1998)، وهي: 1- ذكاء مرتفع جداً: وهو الذي تقع درجته الخام مقابل المئين 95 أو أعلى.

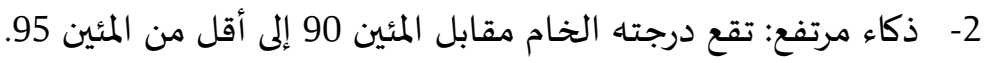

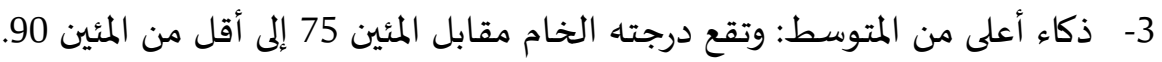

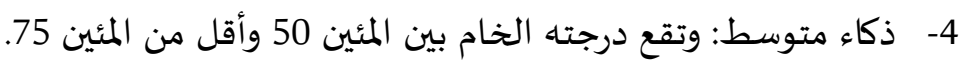

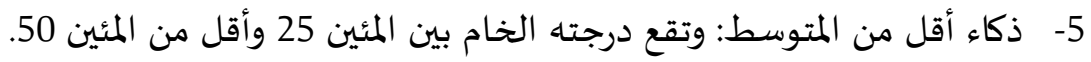
6- ذكاء منخفض: وتقع درجته الخام أقل من المئين 25.

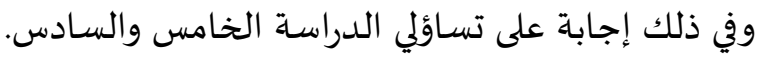


وحيث أكدت النتائج صلاحية الاختبار للتطبيق من خلال التأكد من جودة خصائصها السيكومترية في ضوء

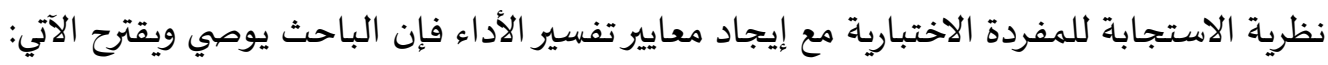

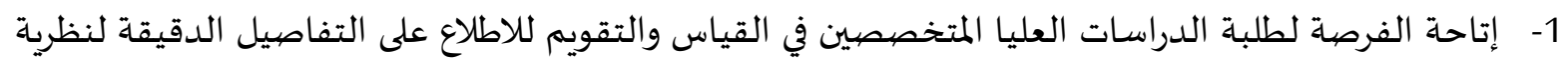
الاستجابة للمفردة، وذلك من خلال تضمين مقررات المناهج موضوع تطبيقات نظرية الاستجابة للمفردة

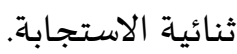

2- الاهتمام بتدريب طلبة الدراسات العليا أثناء الدراسة المنهجية على استخدام تطبيقات نظرية الاستجابة

$$
\text { كما للمفردة وتطبيق ما تم دراسته في الجانب النظري. }
$$

1. استخدام اختبار سنجدرس أومن في اختياروتصنيف الطلاب ذوي القدرات العقلية العليا في وزارة التعليم.

$$
\text { 2. استخدام الاختبار للكشف عن ذكاء الموهوبين في مراكزر رعاية الموهوبين. }
$$

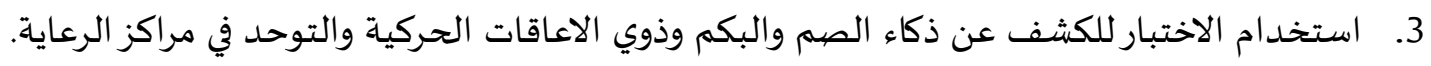

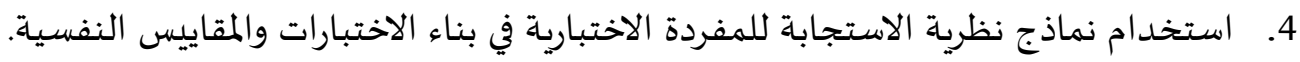

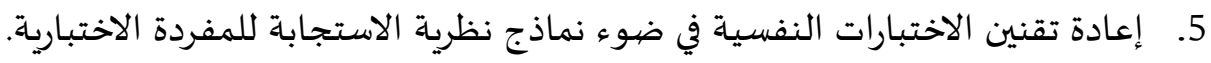

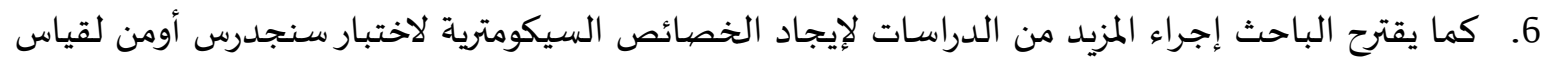
الذكاء الغير لفظي وفق نظرية الاستجابة للمفردة على الفئات العمرية الأخرى من طلبة المرحلة الابتدائية والمرحلة المتوسطة وطلاب الجمعة على مستوى مدينة مكة المكرمة.

- إليانا، أر. جي. (2017). النظرية والتطبيق في نظرية الاستجابة للمفردة. ترجمة عبد الله الكيلاني، وإسماعيل البرصان. دار جامعة الملك سعود للنشر. - بيكر، فريدرك، ب. (2010). أسس نظرية الاستجابة للمفردة. ترجمة الطريري، عبد الرحمن سليمان، أبو هاشم، السيد، شلبي، سوسن. النشر العلمي: جامعة الملك سعود. الثبيتي، عبد الله عيضها. (2016). تقنين اختبار سنجدرس أومن لقياس الذكاء غير اللفظي على طلاب المرحلة الثانوية بمدنية الطائف. رسالة غير منشورة، كلية التربية، جامعة أم القرى. الزهراني، عبد الرحمن جمعان. (2016). تقنين اختبار سنجدرس أومن لقياس الذكاء غير اللفظي على طلاب المابه المرحلة الثانوية في مدينة مكة المكرمة. رسالة غير منشورة. كلية التربية، جامعاة أم القرى.

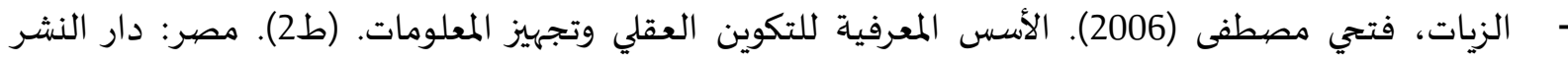

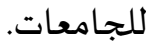
صديق، لينا عمر (2007). الأداء العقلي المعرفي لدى فاقدات السمع والعاديات بالمرحلة المتوسطة. (رسالة ماجستير غير منشورة)، جامعة بنها: كلية التربية. - الطريري، عبد الرحمن سليمان. (1418). القياس النفسي والتربوي نظريته، أسساه، تطبيقاته. مكتبة الرشد،

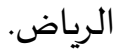


علام، صلاح الدين (2005) نماذج الاستجابة للمفردة الاختبارية أحادية البعد ومتعددة الأبعاد وتطبيقاتها في القياس النفسي والتربوي. دار الفكر العربي: القاهرة.

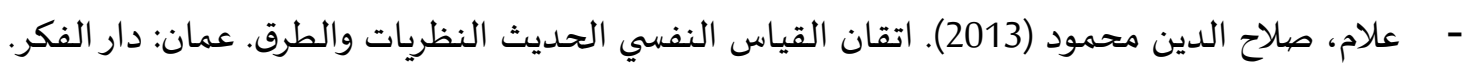
- فرج، صفوت (1980). القياس النفسي. عمان: دار الفكر العربي. - كروكر، ليندا؛ الجينا، جيمس. (2009). مدخل إلى نظرية القياس التقليدية والمعاصرة. ترجمة زينات يوسف. دارس دار الفكر: عمان. موسى، فاتن فاروق (1994). علاقة الذكاء غير اللفظي بالتحصيل الدراسي لدى الصهم والأسوياء. (رسالة ماجستير غير منشورة). مصر: جامعة الزقازيق، كلية التربية.

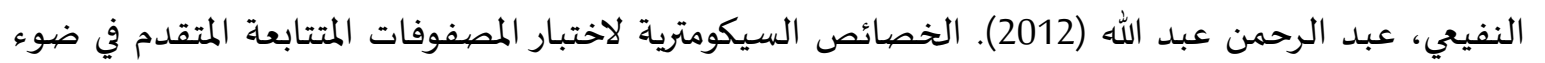
نظرية الاستجابة للمفردة الاختبارية. بحث منشور. مجلة كلية التربية: العدد 147، 1انديد، جامعة الأزهر.

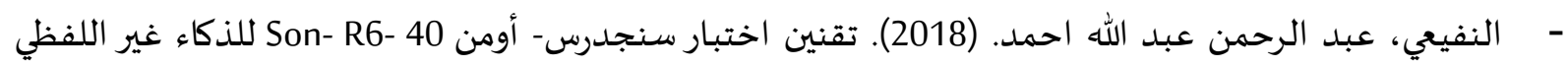

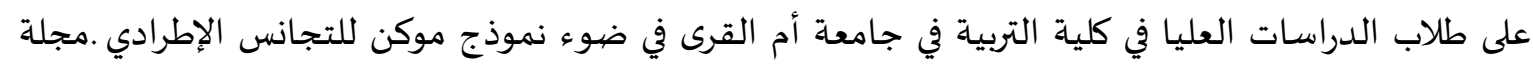
البحث العلمي في التربية، ع19, رج1. 292-249

ثانياً- المراجع بالإنجليزية:

- Alastair, P. and Hutchinson, G. "Calibrating graded assessment: Rash parcial credit analysis of performance in writing", Language Testing, 1987, 4, $72-91$.

- Berge, J. M. F. ten \& Kiers, H. A. L. (1991). A numerical approach to the approximate and the exact minimum rank of a covariance matrix. Psychometrika, 56, 309- 315.

- Choi, I. C. (1992) An Application of Item Response Theory to Language Testing, Theoretical Studies in Second Language Acquisition Vol. 2, Peter Lang, New York.

- Croker, I. M., \& Algina, J. (1986). Introduction to classical \& modern test theory. Orlando, FL: Harcourt Brace Jovanovich.

- Embretson, S. E., \& Reise, S. P. (2000). Item response theory for psychologists. Mahwah, NJ: Lawrence Erlbaum Associates.

- Fraser, C, \& McDonald, R. P. (2003). NOHARM 3.0. Available at: http://people.niagaracollege.ca/ cfraser/download/.

- Gary, R. Vandbos, P. (2013). APA Dictionary Clinical Psychology. Washinton: American Psychological Association.

- Guyer, R., \& Thompson, N. (2012). [user's manual and A computer program] for Xcaliber item response theory calibration software version 4.1.7. St. Paul MN: Assessment System Corporation

- Hamblcton, R. K., \& Swaminathan, H. (1985).' Item response theory: Principles and applications. Boston: Kluwer. 
- Hambleton, R. K. (1989). Principles and selected applications of item response theory. In R. L. Linn (Ed.), Educational measurement (pp. 147-200). Macmillan Publishing Co, Inc; American Council on Education.

- Huysman, K. P. A. (2010). Het normeringsonderzoek SON- R 6- 40. Heymans Instituut, RUG: Intern Verslag.

- Kim, S., Cohen, A., \& Lin, Y. (2005). LDID:Local dependence indices for dichotomous items (a computer program]. The University of Georgia: Scientific software.

- Kumagai, R. (2017). EasyEstimation (Ver.2.0.0). Tohoku University. Japan

- Laros, J. A. (2013). Evidencias de validade convergentedo SON- R6- 40, um teste nao- verbal de inteligencia.universidade de brasilia.

- Lorenzo- seva, U.\& Ferrando, P.J. (2006). FACTOR: A computer program to fit the exploratory factor analysis model. Behavior Research Methods Instruments \& Computers, 38(1), 88- 91.

- Rust, J, \& Golombok, S. (1990). Modern Psychometric the science of Psychological Assessment. Second Edition.

- Stout, W. (2005). DIMTEST (Version 2.0) [Computer software). Champaign, IL: The William Stout Institute for Measurement.

- Tellegen, P. J\& Laros, J.A (2008). Evaluatie van de onderzoeksgegevens van de SON- I. Heymans Instituut, RUG: Intern Verslag.

- Tellegen, P. J\& Laros, J.A (2014).Snijder- Oomen Niet- verbale intelligentietest SON- R6- 40. III. Nederlands- Duitse normen 2014. Amsterdam: Hogrefe uitgevers.

- Xu, J., Zhang, H., Du, Y. \& Tellegen, P.J. (2011). A Review on the Development and Application of SON test. Psychological science China (aangeboden).

- Yen, W. M. (1984). Effects of local item dependence on the fit and equating performance of the threeparameter logistic model. Applied Psychological Measurement, 8, 125- 145. 